Fernanda de Albuquerque Melo Nogueira ${ }^{\mathrm{a}, \mathrm{b}}$ (iD) https://orcid.org/0000-0003-0331-3873

Celia Landmann Szwarcwald ${ }^{c}$ (iD) https://orcid.org/0000-0002-7798-2095

Gisele Nogueira Damacena (iD) https://orcid.org/0000-0002-7059-3353

a Fundação Oswaldo Cruz (Fiocruz), Instituto de Comunicação e Informação Científica e Tecnológica em Saúde, Programa de Pós Graduação em Informação e Comunicação em Saúde. Rio de Janeiro, RJ, Brasil.

${ }^{\mathrm{b}}$ Instituto Nacional do Câncer José Alencar Gomes da Silva (Inca), Coordenação de Prevenção e Vigilância, Área Técnica Ambiente, Trabalho e Câncer. Rio de Janeiro, RJ, Brasil.

' Fundação Oswaldo Cruz (Fiocruz). Instituto de Comunicação e Informação Científica e Tecnológica em Saúde. Rio de Janeiro, RJ, Brasil.

Contato:

Fernanda de Albuquerque Melo Nogueira

E-mail:

fernanda.nogueira@inca.gov.br

Os autores informam que o trabalho foi baseado em tese de doutorado de Fernanda de Albuquerque Melo Nogueira intitulada Estudo sobre condições de vida, trabalho e saúde de trabalhadores agrícolas no Brasil: uma análise dos dados da Pesquisa Nacional de Saúde, 2013, defendida em 2020 no programa de pós-graduação em Informação, Comunicação em Saúde, da Fundação Oswaldo Cruz.

Os autores informam que o trabalho não foi apresentado em evento científico.

Os autores declaram que o trabalho não foi subvencionado e que não há conflitos de interesses.

\section{Exposição a agrotóxicos e agravos à saúde em trabalhadores agrícolas: o que revela a literatura?}

\author{
Exposure to pesticides and agricultural workers' health: \\ what does literature reveal?
}

\section{Resumo}

Introdução: a relação entre agrotóxicos e agravos à saúde tem sido investigada em diferentes contextos. Objetivo: reunir evidência científica relevante sobre agravos à saúde associados à exposição ocupacional aos agrotóxicos. Métodos: revisão de literatura de estudos publicados entre 2000 e 2017, nas bases PubMed, Embase e LILACS. Estabeleceu-se como critérios de elegibilidade: a) estudos observacionais; b) população de trabalhadores agrícolas; c) exposição ocupacional; d) agravos à saúde definidos como desfecho; e) comparação estatística de expostos com não expostos; f) idioma inglês, português ou espanhol. Resultados: 59 publicações foram elegíveis 33 estudos transversais, 22 de coorte e 4 caso-controle. Discussão: os estudos indicam que trabalhadores rurais apresentam maior risco para alguns agravos crônicos (câncer, doenças mentais, neurológicas, endócrinas, renais, auditivas, respiratórias e autoimunes), efeitos subclínicos (danos genéticos e alterações bioquímicas) e sinais e sintomas clínicos de intoxicação aguda. Também foram identificadas limitações dos estudos quanto à avaliação da exposição e do desfecho, delineamento e amostragem. Conclusão: as evidências sugerem a necessidade de se complementar a avaliação da saúde dos trabalhadores expostos aos agrotóxicos utilizando biomarcadores de efeito de genotoxicidade e citotoxicidade, a fim de promover e ampliar a vigilância da exposição e das intoxicações crônicas e suas prevenções.

Palavras-chave: agrotóxicos; efeitos adversos; intoxicação; agricultores; saúde do trabalhador.

\begin{abstract}
Introduction: the association between pesticides and health effects has been investigated in several different contexts. Objective: to gather relevant scientific evidence regarding health effects associated to occupational exposure to pesticides. Methods: literature review of studies published between 2000 and 2017 on PubMed, Embase and LILACS. We adopted the following eligibility criteria: a) observational studies; b) population of agricultural workers; c) occupational exposure to pesticides; d) health effects defined as outcome; e) statistical comparison between exposed and non-exposed subjects; f) English, Portuguese or Spanish language. Results: of 59 papers selected, 33 were cross-sectional studies, 22 cohort studies and 4 case-control studies. Discussion: the studies indicated that rural workers presented higher risk for some chronic diseases (cancer, mental, neurological, endocrine, kidney, hearing, respiratory and autoimmune), subclinical effects (genetic damages and biochemical changes) and clinical signs and symptoms of acute pesticide poisoning. We also identified study limitations concerning design and sampling, assessment of exposure and outcome. Conclusion: the evidences suggest the need to complement health evaluation of workers exposed to pesticides using effect biomarkers of genotoxicity and cytotoxicity in order to promote and expand surveillance of pesticides exposure and chronic intoxications, as well as their prevention.
\end{abstract}

Keywords: pesticides; adverse effects; poisoning; farmers; occupational health. 


\section{Introdução}

As atividades agrícolas e de pecuária sofreram profundas transformações ao longo do tempo nos seus modos de produzir alimentos ${ }^{1}$.

O século XX foi um marco histórico para o sistema de produção agrícola mundial, caracterizando-se pela mecanização, divisão social do trabalho e uso intensivo de agroquímicos, resultando em produção em larga escala - especialmente por meio de monocultivos, favorecendo os grandes latifundiários e empresários em detrimento dos pequenos agricultores e camponeses tradicionais. O uso de agrotóxicos impôs-se como uma necessidade de mercado ${ }^{2}$, e os danos sociais, ambientais e à saúde humana, gerados por essa "nova" agricultura, propiciaram aumento da concentração fundiária, exploração da mão-de-obra no campo, expulsão dos agricultores para a periferia dos grandes centros urbanos e pobreza rural; avanços das monoculturas sobre reservas florestais, terras indígenas e áreas de proteção ambiental; contaminação de águas, do ar, do solo e dos alimentos, com perda da biodiversidade e extinção de espécies e envenenamento dos agricultores pelo uso intensivo de insumos químicos ${ }^{3}$.

Os agroquímicos são produtos químicos sintéticos empregados na agropecuária com diversas finalidades de uso. Compreendem adubos químicos ou fertilizantes, produtos veterinários, hormônios sintéticos, agrotóxicos e outros. Dentre os principais insumos químicos utilizados na agricultura têm-se os agrotóxicos, definidos como qualquer substância ou mistura de substâncias químicas ou biológicas empregados com o objetivo de repelir, destruir ou controlar pragas ou regular o crescimento da planta, podendo ser classificados segundo a finalidade como inseticidas, fungicidas, rodenticidas e herbicidas, entre outras. No entanto, por possuírem toxicidade intrínseca, são reconhecidos como agentes tóxicos à saúde humana e ambiental ${ }^{4}$.

Estudos experimentais demonstraram que a ocorrência de agravos à saúde em humanos decorrente da exposição aos agrotóxicos depende do tipo de ingrediente ativo (IA), da dose administrada, da via de penetração no organismo, do tempo de exposição ao IA e da susceptibilidade individual ${ }^{5}$. Dentre os mecanismos de ação dos IA de agrotóxicos sobre o organismo, a literatura científica destaca os seguintes: a) redução das atividades das enzimas acetilcolinesterase e butirilcolinesterase ${ }^{5}$; b) desregulação endócrina ${ }^{6}$; c) genotoxicidade e alterações genéti$\operatorname{cas}^{7}$; d) indução de carcinogênese ${ }^{8}$; d) estresse oxidativo $^{9} \mathrm{e}$ f) imunossupressão ${ }^{10}$.

Os resíduos de agrotóxicos podem afetar a cadeia alimentar e atingir rios, lagos, mares, reservas de mananciais e lençóis freáticos, contaminando o solo e os alimentos ${ }^{11}$. Estudos científicos revelaram resíduos de agrotóxicos na urina ${ }^{12}$, sangue e leite humano ${ }^{13}$.

Segundo Breilh ${ }^{14}$, os processos de trabalho no campo (agricultura), os modos de produção agrícola, a situação cultural e as relações sociais estabelecidas estão inseridas em diferentes contextos histórico, político, social e econômico, determinando os modos de viver das populações rurais. A combinação desses determinantes gera níveis/graus de exposição aos agrotóxicos diferenciados, podendo ocasionar adoecimento. Nesse sentido, as áreas agrícolas são consideradas locais de alto risco em função do uso de agrotóxicos no cultivo de alimentos e, portanto, a população agrícola que lá reside ou trabalha torna-se um grupo extremamente vulnerável devido à presença desses agentes que podem ocasionar danos severos à sua saúde ${ }^{15}$.

Mediante o exposto, o presente trabalho teve por objetivo reunir evidência científica relevante sobre os principais agravos à saúde estudados na população de trabalhadores da agricultura, pecuária e afins, associados à exposição aos agrotóxicos.

\section{Métodos}

A revisão desenvolveu-se em cinco etapas:

\section{Etapa 1}

Busca por estudos elegíveis e identificação das bases de dados bibliográficas a partir dos seguintes critérios de inclusão: a) estudos observacionais de coorte, caso-controle e transversais, publicados entre os anos 2000 e 2017. O período da busca foi definido para se obter estudos mais recentes referentes ao tema; b) população de interesse composta por agricultores (trabalhadores que praticam agricultura), criadores de animais (trabalhadores da pecuária) e aplicadores de agrotóxicos (trabalhadores que aplicam agrotóxicos); c) exposição, definida pelo uso de agrotóxicos no trabalho; d) desfecho, definido como agravos à saúde; e) uso de testes estatísticos para comparação de expostos com não expostos (considerou-se o parâmetro $\mathrm{p}$ - valor $<0,05$ para significância estatística das associações); f) estudos escritos nos idiomas inglês, português ou espanhol. A busca ocorreu entre setembro e dezembro de 2017 nas seguintes bases bibliográficas: PubMed, Embase e LILACS (BVS). As estratégias de busca foram específicas para cada base bibliográfica. No PubMed os descritores foram: (c((c"Agrochemicals/adverse effects”[Medical Subject Headings - MeSH])) OR ("Agrochemicals/poisoning" [Mesh])) OR ("Agrochemicals/toxicity"[Mesh])) OR ("Agrochemicals health effects")) OR ("Agrochemicals health problems")) OR ("Agrochemicals health symptoms")) OR ("Agrochemicals chronic effects")) AND ("Farmers"[Mesh]) AND ((“2000/01/01”[PDAT] : 
“2017/12/31”[PDAT]) AND “humans”[Mesh Terms]. No Embase, foram identificados os descritores "ENTRY" relacionados a agroquímicos, agravos à saúde e agricultores, a partir da estratégia de busca: (('pesticide'/ $\exp / \mathrm{mj}$ OR 'agricultural chemical'/exp/mj) AND ('adverse outcome'/exp/mj OR 'intoxication'/exp/mj) AND ('agricultural worker'/exp/mj) AND [2000-2017]/ py. Na LILACS, foram utilizados os descritores (Decs) / palavras chave: ("agroquímicos" OR "pesticidas" OR “agrotóxicos”) AND ("fazendeiros" OR "agricultores” OR "trabalhador rural”) AND ("doenças" OR "agravos à saúde” OR “condições de saúde” OR "problemas de saúde” OR “intoxicação” OR “envenenamento”) AND (collection:(“06-national/BR” OR “05-specialized”) OR db:(“LILACS” OR “MEDLINE”)) AND (db:(“LILACS”) AND limit:(“humans”) AND la:(“en” OR “pt” OR “es”) AND type:(“article”).

\section{Etapa 2}

Triagem dos estudos pela leitura do título e dos resumos. Em seguida, confirmação da elegibilidade por leitura completa feita por dois pesquisadores que realizaram a leitura de forma independente.

\section{Etapa 3}

Busca manual de estudos adicionais a partir das listas de referências dos estudos selecionados.

\section{Etapa 4}

Extração e tabulação dos dados dos estudos selecionados em uma planilha com as informações sobre: autor, ano, local, população estudada, amostragem, mensuração da exposição e do desfecho, variáveis de confusão, análise estatística e resultados.

\section{Etapa 5}

Avaliação crítica dos estudos selecionados.

\section{Resultados}

Foram identificados 132 estudos (21 na base de dados Embase, 45 na LILACS e 66 no PubMed). Desses, foram excluídos 78 por não atenderem aos critérios de inclusão, restando 54 publicações. Do total de artigos excluídos, 14 eram estudos de revisão, 6 estudos qualitativos, 3 estudos de caso, 5 estudos ecológicos, 6 estudos de intervenção em comunidades, 15 estudos descritivos, 12 estudos não relacionados à exposição ou ao desfecho investigados, 6 estudos que não avaliaram a população agrícola, 5 estudos na modalidade de ensaio, 3 estudos sobre validação de metodologias, 1 estudo com publicação apenas no abstract, 1 estudo em duplicata e 1 estudo sem Digital Object Identifier (DOI) localizado. Foram incluídos 5 estudos por meio de busca manual totalizando 59 estudos (Figura 1).

O Quadro 1 apresenta todos os estudos selecionados de acordo com local, delineamento e população estudada. Foram identificados 33 estudos transversais, 22 de coorte e 4 casos-controle, segundo informações referidas pelos autores. A maioria foi de estudos internacionais.

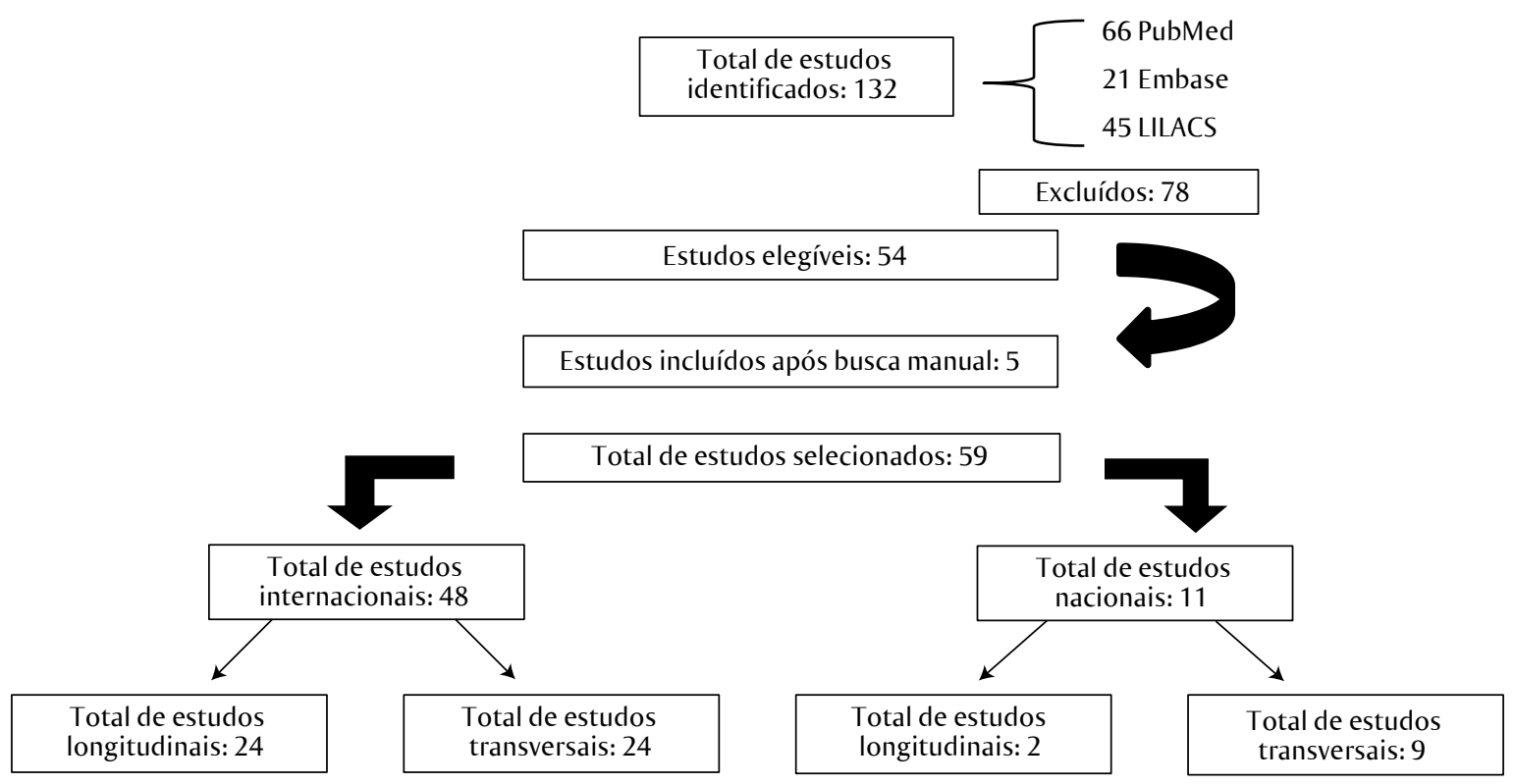

Figura 1 Fluxo de seleção dos artigos 
Quadro 1 País, ano de publicaçao, delineamento e população estudada nos estudos selecionados

\begin{tabular}{|c|c|c|c|}
\hline Autor(es) & País, ano & Delineamento & População estudada* \\
\hline Moisan et al. ${ }^{16}$ & França, 2015 & Caso-controle & $\begin{array}{l}133 \text { agricultores com DP/parkinsonismo e } 298 \text { controles } \\
\text { entre } 50 \text { a } 79 \text { anos }\end{array}$ \\
\hline Nielsen et al. ${ }^{17}$ & EUA, 2017 & Transversal & 38 aplicadores de agrotóxicos com $\geq 30$ anos \\
\hline Nguyen et al. ${ }^{18}$ & EUA, 2015 & Coorte & 136 agricultores e 116 controles com $\geq 30$ anos \\
\hline Zhang et al. ${ }^{19}$ & China, 2015 & Caso-controle & $\begin{array}{l}121 \text { agricultores intoxicados por agrotóxicos e } 80 \text { controles } \\
\text { com }>18 \text { anos }\end{array}$ \\
\hline Jamal et al. ${ }^{20}$ & India, 2016 & Transversal & $\begin{array}{l}187 \text { aplicadores de agrotóxicos e } 187 \text { controles entre } \\
16 \text { e } 80 \text { anos }\end{array}$ \\
\hline Sunwook et al. ${ }^{21}$ & EUA, 2016 & Coorte & 77 agricultores e 59 controles entre 30 e 70 anos \\
\hline Campos et al. ${ }^{22}$ & Brasil, 2017 & Transversal & 869 agricultores/moradores rurais com $\geq 18$ anos \\
\hline Harrison \& Ross ${ }^{23}$ & Inglaterra, 2016 & Transversal & $\begin{array}{l}127 \text { produtores de ovelha expostos a OF e } 78 \text { controles entre } \\
18 \text { e } 70 \text { anos }\end{array}$ \\
\hline Kim et al. ${ }^{24}$ & $\begin{array}{l}\text { Coreia do Sul, } \\
2014\end{array}$ & Transversal & $\begin{array}{l}1.895 \text { agricultores homens que participaram do } \\
\text { "Registro Domiciliar de Agricultura" entre } 30 \text { e } 70 \text { anos }\end{array}$ \\
\hline Lemarchand et al. ${ }^{25}$ & França, 2016 & Coorte & $\begin{array}{l}81.961 \text { agricultores filiados ao seguro Mutualité Sociale } \\
\text { Agricola com } \geq 18 \text { anos }\end{array}$ \\
\hline Bonner et al. ${ }^{26}$ & EUA, 2005 & Coorte & $\begin{array}{l}58 \text { agricultores expostos a agrotóxicos e } 58 \text { controles } \\
\text { (coorte do AHS) (sem informação sobre idade, apenas } \\
\text { faixas etárias na tabela de resultados) }\end{array}$ \\
\hline Boada et al. ${ }^{27}$ & Espanha, 2016 & Caso-controle & $\begin{array}{l}140 \text { agricultores com casos de CA de bexiga primários e } \\
206 \text { controles de base hospitalar (sem informação sobre } \\
\text { idade. Apenas faixas etárias na tabela de resultados) }\end{array}$ \\
\hline Boulanger et al. ${ }^{28}$ & França, 2017 & Coorte & $\begin{array}{l}148.051 \text { agricultores filiados ao seguro Mutualité Sociale } \\
\text { Agricole com } \geq 18 \text { anos }\end{array}$ \\
\hline Piccoli et al. ${ }^{29}$ & Brasil, 2016 & Transversal & 275 agricultores com $\geq 18$ anos \\
\hline Medda et al. ${ }^{30}$ & Itália, 2017 & Transversal & 177 agricultores e 74 controles com $>18$ anos \\
\hline La Verda et al. ${ }^{31}$ & EUA, 2015 & Coorte & $\begin{array}{l}8.365 \text { aplicadores de agrotóxicos da coorte do AHS } \\
\text { com } 20 \text { anos ou mais }\end{array}$ \\
\hline Lebov et al. ${ }^{32}$ & EUA, 2015 & Coorte & $\begin{array}{l}31.142 \text { esposas de aplicadores de agrotóxicos com } \\
\geq 18 \text { anos (coorte do AHS) }\end{array}$ \\
\hline Hoppin et al. ${ }^{33}$ & EUA, 2017 & Coorte & $\begin{array}{l}22.134 \text { aplicadores de agrotóxicos que participaram do } \\
\text { AHS (2005 e 2010) com } 20 \text { anos ou mais }\end{array}$ \\
\hline Bazilio et al..$^{34}$ & Brasil, 2012 & Transversal & 33 agricultores com $\geq 18$ anos \\
\hline De Sena et al..$^{35}$ & Brasil, 2013 & Transversal & 351 agricultores com $\geq 18$ anos \\
\hline Parks et al. ${ }^{36}$ & EUA, 2016 & Coorte & $\begin{array}{l}\text { Esposas de aplicadores de agrotóxicos ( } 24.018 \text { não } \\
\text { casos de AR e } 132 \text { casos incidentes) com } 20 \text { anos ou mais }\end{array}$ \\
\hline $\begin{array}{l}\text { García-García } \\
\text { et al. }{ }^{37}\end{array}$ & Espanha, 2016 & Coorte & 189 agricultores expostos e 91 controles com $\geq 18$ anos \\
\hline $\begin{array}{l}\text { Aroonvilairat } \\
\text { et al. }{ }^{38}\end{array}$ & Tailândia, 2015 & Transversal & 64 agricultores e 60 controles entre 20 e 60 anos \\
\hline Rocha et al. ${ }^{39}$ & Brasil, 2015 & Coorte & 54 agricultores e 108 controles sem informação sobre idade \\
\hline Alves et al..$^{40}$ & Brasil, 2016 & Transversal & $\begin{array}{l}77 \text { agricultores com idade média de } 45 \text { anos e } 60 \text { controles } \\
\text { com idade média de } 44 \text { anos }\end{array}$ \\
\hline $\begin{array}{l}\text { Hongsibsong } \\
\text { et al. }{ }^{41}\end{array}$ & Tailândia, 2017 & Transversal & 103 agricultores e 47 controles entre 25 e 65 anos \\
\hline Lebailly et al. ${ }^{42}$ & França, 2015 & Coorte & 26 agricultores expostos e 29 controles com $\geq 20$ anos \\
\hline $\begin{array}{l}\text { De Oliveira e } \\
\text { Ehrhard }^{43}\end{array}$ & Brasil, 2015 & Coorte & 33 agricultores $\geq 18$ anos em contato direto com agrotóxicos \\
\hline
\end{tabular}


Quadro 1 Continuação...

\begin{tabular}{|c|c|c|c|}
\hline Autor(es) & País, ano & Delineamento & População estudada* \\
\hline Rosales $^{44}$ & Peru, 2015 & Transversal & $\begin{array}{l}59 \text { agricultores expostos a agrotóxicos e } 50 \text { controles } \\
\text { com }>18 \text { anos }\end{array}$ \\
\hline $\begin{array}{l}\text { Carbajal-López } \\
\text { et al. }{ }^{45}\end{array}$ & México, 2016 & Transversal & $\begin{array}{l}111 \text { agricultores expostos a agrotóxicos com idade média de } \\
46 \text { anos e } 60 \text { não expostos com idade média de } 38 \text { anos }\end{array}$ \\
\hline $\begin{array}{l}\text { Simoniello } \\
\text { et al. }{ }^{46}\end{array}$ & Argentina, 2010 & Transversal & $\begin{array}{l}45 \text { aplicadores de agrotóxicos com idade média de } 40 \text { anos, } \\
50 \text { agricultores com idade média de } 34 \text { anos e } 50 \text { controles } \\
\text { com idade média de } 37 \text { anos }\end{array}$ \\
\hline Tumer et al. ${ }^{47}$ & Turquia, 2016 & Transversal & $\begin{array}{l}58 \text { agricultores expostos a agrotóxicos e } 58 \text { controles } \\
\text { com }>18 \text { anos }\end{array}$ \\
\hline $\begin{array}{l}\text { Saad-Hussein } \\
\text { et al. }{ }^{48}\end{array}$ & Egito, 2017 & Transversal & $\begin{array}{l}50 \text { agricultores expostos a múltiplas misturas de agrotóxicos } \\
\text { com idade média de } 46 \text { anos e } 50 \text { controles com idade média } \\
\text { de } 45 \text { anos }\end{array}$ \\
\hline Mackness et al. ${ }^{49}$ & $\begin{array}{l}\text { Reino Unido, } \\
2003\end{array}$ & Caso-controle & $\begin{array}{l}175 \text { criadores de animais com doença crônica com idade } \\
\text { média de } 54 \text { anos e } 234 \text { controles com idade média de } \\
52 \text { anos }\end{array}$ \\
\hline Rusieki et al. ${ }^{50}$ & EUA, 2017 & Coorte & $\begin{array}{l}596 \text { homes aplicadores de agrotóxicos, homens da coorte } \\
\text { AHS com > } 20 \text { anos. }\end{array}$ \\
\hline $\begin{array}{l}\text { Gómez-Martín } \\
\text { et al. }{ }^{51}\end{array}$ & Espanha, 2015 & Coorte & 39 agricultores que trabalhavam em estufas com $>20$ anos \\
\hline Zeljezic et al. ${ }^{52}$ & Croácia, 2015 & Transversal & $\begin{array}{l}30 \text { agricultores expostos ocupacionalmente e } 30 \text { controles } \\
\geq 20 \text { anos }\end{array}$ \\
\hline Lerro et al. ${ }^{53}$ & EUA, 2017 & Coorte & 30 agricultores e 10 controles com $\geq 40$ anos (coorte AHS) \\
\hline Bayrami et al. ${ }^{54}$ & Irã, 2012 & Transversal & 40 agricultores expostos a OF e 40 controles com $\geq 15$ anos \\
\hline Madani et al. ${ }^{55}$ & Argélia, 2016 & Transversal & $\begin{array}{l}50 \text { agricultores expostos a agrotóxicos e } 60 \text { controles } \\
\text { entre } 30 \text { e } 50 \text { anos }\end{array}$ \\
\hline Wang et al..$^{56}$ & China, 2016 & Coorte & $\begin{array}{l}20 \text { agricultores adultos e } 15 \text { controles } \\
\text { (sem informação sobre idade) }\end{array}$ \\
\hline Costa et al. ${ }^{57}$ & Itália, 2015 & Transversal & 55 agricultores homens com $>18$ anos \\
\hline Ramírez e Cuenca ${ }^{58}$ & Costa Rica, 2001 & Transversal & 32 mulheres expostas e 39 não expostas, entre 16 e 57 anos \\
\hline Pakravan et al. ${ }^{59}$ & Irã, 2016 & Coorte & $\begin{array}{l}36 \text { agricultores homens com idade entre } 25 \text { e } 85 \text { anos } \\
\text { expostos a OF }\end{array}$ \\
\hline Dasgupta et al. ${ }^{60}$ & Vietnã, 2007 & Transversal & 190 agricultores $\geq 15$ anos \\
\hline Mancini et al. ${ }^{61}$ & Índia, 2005 & Transversal & $\begin{array}{l}97 \text { agricultores ( } 50 \text { mulheres com idade média de } \\
36,5 \text { anos e } 47 \text { homens com idade média de } 37 \text { anos) }\end{array}$ \\
\hline Neupane et al. ${ }^{62}$ & Nepal, 2014 & Transversal & $\begin{array}{l}90 \text { agricultores homens com idade média de } 42 \text { anos e } \\
90 \text { controles homens com idade média de } 38 \text { anos }\end{array}$ \\
\hline $\begin{array}{l}\text { Oesterlund } \\
\text { et al. }{ }^{63}\end{array}$ & Uganda, 2014 & Transversal & 317 agricultores com idade média de 42 anos \\
\hline Faria et al. ${ }^{64}$ & Brasil, 2009 & Transversal & 290 agricultores na $1^{\text {a }}$ etapa e 246 na $2^{\text {a }}$ etapa com $\geq 16$ anos \\
\hline $\begin{array}{l}\text { Muñoz-Quezada } \\
\text { et al. }{ }^{65}\end{array}$ & Chile, 2017 & Transversal & $\begin{array}{l}114 \text { agricultores e } 93 \text { não agricultores (controles). A } \\
\text { população do estudo tinha idade média de } 42 \text { anos }\end{array}$ \\
\hline Khan e Damalas ${ }^{66}$ & Paquistão, 2015 & Transversal & 318 agricultores com $>20$ anos \\
\hline Salameh e Saleh ${ }^{67}$ & Líbano, 2004 & Transversal & $\begin{array}{l}89 \text { agricultores expostos com idade média de } 40 \text { anos e } \\
88 \text { não expostos com idade média de } 36 \text { anos }\end{array}$ \\
\hline Souza et al. ${ }^{68}$ & Brasil, 2011 & Transversal & $\begin{array}{l}298 \text { sujeitos com } \geq 18 \text { anos moradores e/ou agricultores em } \\
\text { três áreas rurais }\end{array}$ \\
\hline Jacobson et al. ${ }^{69}$ & Brasil, 2009 & Transversal & 151 agricultores familiares $\geq 15$ anos \\
\hline Siqueira et al. ${ }^{70}$ & Brasil, 2013 & Transversal & 343 agricultores com $\geq 18$ anos \\
\hline
\end{tabular}

(Continua) 
Quadro 1 Continuação...

\begin{tabular}{|c|c|c|c|}
\hline Autor(es) & País, ano & Delineamento & População estudada* \\
\hline Alavanja et al. ${ }^{71}$ & EUA, 2014 & Coorte & $\begin{array}{l}54.306 \text { aplicadores de agrotóxicos da coorte AHS com idade } \\
\text { que variou entre menos que } 45 \text { e } 70 \text { anos ou mais }\end{array}$ \\
\hline Lerro et al. ${ }^{72}$ & EUA, 2014 & Coorte & $\begin{array}{l}32.345 \text { esposas de aplicadores de agrotóxicos da coorte AHS } \\
\text { com } \geq 35 \text { anos }\end{array}$ \\
\hline Engel et al. ${ }^{73}$ & EUA, 2017 & Coorte & $\begin{array}{l}30.594 \text { mulheres agricultoras participantes da coorte da AHS } \\
\text { com } \geq 18 \text { anos }\end{array}$ \\
\hline Lerro et al. ${ }^{74}$ & EUA, 2015 & Coorte & $\begin{array}{l}33.484 \text { aplicadores de agrotóxicos, homens participantes da } \\
\text { coorte AHS (sem informação sobre idade). }\end{array}$ \\
\hline
\end{tabular}

AHS: Agricultural Health Study; AR: Artrite reumatoide; CA: Câncer; DP: Doença de Parkinson; OF: Organofosforados.

O Quadro 2 apresenta os métodos de avaliação da exposição e dos desfechos empregados nos estudos. Do total, 52 estudos utilizaram questionários para avaliar a exposição aos agrotóxicos, recorrendo às variáveis: uso de agrotóxicos em geral $^{21,28,40,43-45,47,48,54,60,62-64,67-70}$, duração da exposição ${ }^{16,17,19,21-23,28,29,31,36,40,44,48,55,57,61,64,65,67,74}$, frequência de uso/aplicação ${ }^{16,36,45,60,74}$, ocupação ${ }^{16,30,39,46,47,48,49,56,58,67}$, quantidade de agrotóxico utilizado ${ }^{18,28,29,61}$, tipo de IA $^{25-}$ 27,31,33,36,39,40,60-62,65,69,71-74, classe de agrotóxico por finalidade de uso 28,29,31,33,62,69,71,72, grupamento químico (GQ) $)^{22,27,31,38,39,50,54,62,64,65,71,72,73}$ e classificação de toxicidade ${ }^{60,61,63,71,72}$. As quatro últimas informações foram levantadas a partir do nome comercial do produto autorreferido - dois estudos avaliaram a exposição pela ocorrência de episódios autorreferidos de intoxicação aguda/crônica por agrotóxicos ${ }^{19,24}$ e um avaliou a ocorrência de exposição excepcionalmente alta causada por episódio de intoxicação acidental ou não ${ }^{50}$. Faria et al. ${ }^{64}$ avaliaram a exposição aos agrotóxicos segundo uma matriz de exposição.

Quadro 2 Métodos de avaliação da exposição e do desfecho dos estudos selecionados

\begin{tabular}{|c|c|c|}
\hline Autor(es) & Avaliação da Exposição (variáveis) & Avaliação do Desfecho \\
\hline Moisan et al. ${ }^{16}$ & $\begin{array}{l}\text { Duração, intensidade e exposição } \\
\text { cumulativa }\end{array}$ & $\begin{array}{l}\text { Doença de Parkinson (DP) e seus subtipos - } \\
\text { exame clínico neurológico }\end{array}$ \\
\hline Nielsen et al. ${ }^{17}$ & $\begin{array}{l}\text { Tempo de trabalho e aplicação, } \\
\text { principais culturas, EPI }\end{array}$ & $\begin{array}{l}\text { Parkinsonismo (exame clínico e uso da } \\
\text { Escala Unified Parkinson's Disease Rating Scale - UPDRS) }\end{array}$ \\
\hline Nguyen et al. ${ }^{18}$ & $\begin{array}{l}\text { Avaliada a partir da ocupação (agricultor x } \\
\text { não agricultor) }\end{array}$ & $\begin{array}{l}\text { Função cognitiva e alterações neurológicas subclínicas } \\
\text { (NCBT - Neurobehavioral Core Battery Test) }\end{array}$ \\
\hline Zhang et al. ${ }^{19}$ & $\begin{array}{l}\text { Nome comercial, IA, tempo de trabalho, } \\
\text { sinais e sintomas clínicos de intoxicação } \\
\text { por agrotóxicos }\end{array}$ & $\begin{array}{l}\text { Função neurocomportamental - Bateria de Provas } \\
\text { Neurocomportamentais - WHO neurobehavioral core test battery - } \\
\text { NCBT (1986) }\end{array}$ \\
\hline Jamal et al. ${ }^{20}$ & $\begin{array}{l}\text { Avaliada através da ocupação (agricultor e } \\
\text { não agricultor) e pelo uso de OF (sim/não) }\end{array}$ & $\begin{array}{l}\text { Função neurocomportamental: Inventário subjetivo de } \\
\text { neurocognição e parâmetros bioquímicos }\end{array}$ \\
\hline Sunwook et al. ${ }^{21}$ & $\begin{array}{l}\text { Exposição a pesticidas ao longo da vida e } \\
\text { anos de exposição ocupacional }\end{array}$ & $\begin{array}{l}\text { Comprometimento neurológico: avaliação do equilíbrio } \\
\text { postural em posição vertical }\end{array}$ \\
\hline Campos et al. ${ }^{22}$ & $\begin{array}{l}\text { Tipo de IA, tempo de uso, GQ, idade de } \\
\text { início de } \\
\text { uso de agrotóxico }\end{array}$ & $\begin{array}{l}\text { Transtorno Psiquiátrico Menor (TPM): SelfReport Questionnaire } \\
\text { (SRQ-20) e depressão auto-relatada }\end{array}$ \\
\hline Harrison e Ross ${ }^{23}$ & $\begin{array}{l}\text { Tempo de exposição a OF }=\left(n^{\circ} \text { de dias }\right. \\
\text { de uso de OF por ano) } x\left(n^{\circ} \text { de anos que }\right. \\
\text { usaram OF) }\end{array}$ & $\begin{array}{l}\text { Escala de depressão e ansiedade hospitalar, Ansiedade de Beck, } \\
\text { Inventário de depressão, entrevista clínica }\end{array}$ \\
\hline Kim et al. ${ }^{24}$ & $\begin{array}{l}\text { Sinais e sintomas clínicos de intoxicação } \\
\text { aguda. Intoxicação crônica }\end{array}$ & $\begin{array}{l}\text { Tentativa de suicídio: no último ano você já pensou em } \\
\text { machucar o seu corpo ou tirar a sua vida? }\end{array}$ \\
\hline $\begin{array}{l}\text { Lemarchand } \\
\text { et al. }{ }^{25}\end{array}$ & $\begin{array}{l}\text { Tipo de cultura, criação de animais, uso de } \\
\text { agrotóxicos durante a reentrada e colheita }\end{array}$ & $\begin{array}{l}\text { Câncer de próstata: casos incidentes diagnosticados no período } \\
\text { de estudo }\end{array}$ \\
\hline
\end{tabular}


Quadro 2 Continuação...

\begin{tabular}{|c|c|c|}
\hline Autor(es) & Avaliação da Exposição (variáveis) & Avaliação do Desfecho \\
\hline Bonner et al. ${ }^{26}$ & $\begin{array}{l}\text { Tipo de IA, tempo de uso, intensidade } \\
\text { ponderada da exposição para cada IA }\end{array}$ & $\begin{array}{l}\text { Câncer de pulmão: os casos de câncer de pulmão que ocorreram } \\
\text { entre 31/12/2010 e 31/12/2011 }\end{array}$ \\
\hline Boada et al. ${ }^{27}$ & $\begin{array}{l}\text { Dosagem de } 19 \text { metabólitos de OCs no } \\
\text { sangue }\end{array}$ & $\begin{array}{l}\text { Câncer de bexiga: diagnóstico clínico e laudo histopatológico; } \\
\text { polimorfismo genético da GST }\end{array}$ \\
\hline Boulanger et al. ${ }^{28}$ & $\begin{array}{l}\text { Atividades da agricultura e criação de } \\
\text { animais, práticas de higiene no trabalho }\end{array}$ & $\begin{array}{l}\text { Casos incidentes de câncer de bexiga (Classificação } \\
\text { Internacional de Doenças para Oncologia: CID-O-3ED) }\end{array}$ \\
\hline Piccoli et al. ${ }^{29}$ & $\begin{array}{l}\text { IA na urina, frequência, intensidade, tempo } \\
\text { e período de aplicação; tipo e quantidade } \\
\text { de IA }\end{array}$ & $\begin{array}{l}\text { Alterações da função da tireoide: FT4, TT3, TSH; Níveis de CT, } \\
\text { TG e lipídeos total. AChE e BChE }\end{array}$ \\
\hline Medda et al..$^{30}$ & $\begin{array}{l}\text { Exposição ao mancozeb (sim/não), outros } \\
\text { IA, uso de EPI. Dosagem de ETU urinário }\end{array}$ & $\begin{array}{l}\text { Função tireoidiana: exame clínico, US e dosagem de TSH, T3, } \\
\text { FT3, T4, FT4, TgAb, TPOAb e iodo urinário }\end{array}$ \\
\hline LaVerda et al. ${ }^{31}$ & $\begin{array}{l}\text { Duração e frequência da exposição, } \\
\text { exposição cumulativa; tipo de IA, GP e } \\
\text { finalidade de uso }\end{array}$ & $\begin{array}{l}\text { Variações no IMC segundo a classificação da Organização } \\
\text { Mundial da Saúde de } 2007\end{array}$ \\
\hline Lebov et al. ${ }^{32}$ & $\begin{array}{l}\text { IA, finalidade de uso, exposição direta, } \\
\text { indireta, domiciliar e exposição agrícola } \\
\text { sem aplicação }\end{array}$ & $\begin{array}{l}\text { Doença Renal em estágio terminal partir do Sistema de } \\
\text { Informação em Doença Renal dos EUA }\end{array}$ \\
\hline Hoppin et al. ${ }^{33}$ & $\begin{array}{l}\text { Nome comercial e dos IA, tempo de } \\
\text { trabalho na lavoura, descrição das } \\
\text { atividades na fazenda }\end{array}$ & $\begin{array}{l}\text { Sibilo: relato de pelo menos um episódio de sibilância ou chiado } \\
\text { no peito no ano anterior; via questionário }\end{array}$ \\
\hline Bazilio et al. ${ }^{34}$ & $\begin{array}{l}\text { Uso de agrotóxicos em geral. Calculou-se } \\
\text { um índice de exposição }\end{array}$ & $\begin{array}{l}\text { Alterações auditivas medidas pelos Teste de Padrão de Duração } \\
\text { (TPD) e Teste de Gaps-in-Noise (GIN) }\end{array}$ \\
\hline De Sena et al. ${ }^{35}$ & Uso de pesticidas em geral (sim/não) & $\begin{array}{l}\text { Perda auditiva: Meatoscopia, audiometria total liminar e } \\
\text { Qualidade de vida: Short Form } 36 \text { - versão brasileira }\end{array}$ \\
\hline Parks et al. ${ }^{36}$ & $\begin{array}{l}\text { IA, tempo de residência, idade de início } \\
\text { na agricultura, atividades desenvolvidas, } \\
\text { tempo de exposição }\end{array}$ & $\begin{array}{l}\text { Casos incidentes confirmados e prováveis (que usavam } \\
\text { corticóides) de Artrite Reumatoide (AR) }\end{array}$ \\
\hline García-García et al. ${ }^{37}$ & $\begin{array}{l}\text { Uso de agrotóxicos em geral, períodos de } \\
\text { alta e baixa exposição }\end{array}$ & $\begin{array}{l}\text { Parâmetros bioquímicos, hematológicos, ECG, espirometria, } \\
\text { níveis de } \mathrm{AChE/BChE,} \mathrm{queixas} \mathrm{de} \mathrm{saúde}\end{array}$ \\
\hline Aroonvilairat et al. ${ }^{38}$ & Tipo de IA & $\begin{array}{l}\text { AChE e BChE, leucograma, hemograma, lizosina, função renal e } \\
\text { hepática, ensaio mitogênico }\end{array}$ \\
\hline Rocha et al. ${ }^{39}$ & $\begin{array}{l}\text { Avaliada pela ocupação (plantadores de } \\
\text { uva- sim/não), tipo de IA e GP }\end{array}$ & $\begin{array}{l}\text { Alterações nas concentrações sanguíneas de metais (zinco, } \\
\text { chumbo, cobre, níquel, manganês e arsênio) }\end{array}$ \\
\hline Alves et al. ${ }^{40}$ & $\begin{array}{l}\text { Atividade desenvolvida, duração da } \\
\text { aplicação, tipos de agrotóxicos aplicados e } \\
\text { uso de EPI }\end{array}$ & $\begin{array}{l}\text { Danos no DNA, atividade da SOD, polimorfismos genéticos, } \\
\text { parâmetros hematológicos e bioquímicos }\end{array}$ \\
\hline Hongsibsong et al. ${ }^{41}$ & Dosagem de metabólitos de OF na urina & Níveis de AChE e danos no DNA (Ensaio Cometa) \\
\hline Lebailly et al. ${ }^{42}$ & $\begin{array}{l}\text { Período de aplicação de herbicidas, } \\
\text { fungicidas e inseticidas, tempo de } \\
\text { exposição, tipo de cultura }\end{array}$ & Danos no DNA de linfócitos B e T através do Ensaio Cometa \\
\hline $\begin{array}{l}\text { De Oliveira e } \\
\text { Ehrhardt }^{43}\end{array}$ & $\begin{array}{l}\text { Uso de EPI, tempo de exposição, medidas } \\
\text { de higiene adotadas após a aplicação }\end{array}$ & $\begin{array}{l}\text { Alterações na atividade de AChE e BChE antes e após a aplicação } \\
\text { de agrotóxicos }\end{array}$ \\
\hline Rosales $^{44}$ & $\begin{array}{l}\text { Uso de agrotóxicos em geral por } 2 \text { anos } \\
\text { (sim/não) }\end{array}$ & $\begin{array}{l}\text { Atividade de AChE e BChE e danos no DNA (Ensaio Cometa, } \\
\text { teste do MN e aberrações cromossômicas) }\end{array}$ \\
\hline Carbajal-López et al. ${ }^{45}$ & Duração da exposição & $\begin{array}{l}\text { Danos no DNA: Ensaio Cometa, Teste do MN e outras anomalias } \\
\text { nucleares (Tolbert, } 1992 \text { e Holland, 2008). }\end{array}$ \\
\hline Simoniello et al. ${ }^{46}$ & $\begin{array}{l}\text { Exposição direta, exposição indireta e } \\
\text { trabalhadores sem exposição ocupacional }\end{array}$ & $\begin{array}{l}\text { Danos no DNA (Ensaio Cometa, Reparação do DNA), atividade } \\
\text { da AChE e BChE, dosagem de TBARS }\end{array}$ \\
\hline Tumer et al. ${ }^{47}$ & $\begin{array}{l}\text { Tempo de exposição a agrotóxicos (em } \\
\text { anos) e uso de EPI. }\end{array}$ & $\begin{array}{l}\text { Danos no DNA (teste do MN) e presença de polimorfismos } \\
\text { genéticos. }\end{array}$ \\
\hline
\end{tabular}


Quadro 2 Continuação...

\begin{tabular}{|c|c|c|}
\hline Autor(es) & Avaliação da Exposição (variáveis) & Avaliação do Desfecho \\
\hline Saad-Hussein et al. ${ }^{48}$ & $\begin{array}{l}\text { Uso de agrotóxicos (sim/não), atividades } \\
\text { desenvolvidas, uso de EPI, hábitos de } \\
\text { higiene }\end{array}$ & $\begin{array}{l}\text { Danos no DNA (Ensaio Cometa) e Polimorfismos genéticos } \\
\text { (análise de genotipagem) }\end{array}$ \\
\hline Mackness et al. ${ }^{49}$ & $\begin{array}{l}\text { Dar banho de imersão nas ovelhas (sim/ } \\
\text { não) }\end{array}$ & $\begin{array}{l}\text { Doença crônica autorreferida, atividade das enzimas PON1 e } \\
\text { polimorfismos genético }\end{array}$ \\
\hline Rusieki et al..$^{50}$ & $\begin{array}{l}\text { Ocorrência de eventos de alta exposição a } \\
\text { pesticidas (sim/não) }\end{array}$ & Alterações epigenéticas - metilação no DNA \\
\hline Gómez-Martín et al. ${ }^{51}$ & Períodos de baixa e alta exposição & $\begin{array}{l}\text { Metilação do DNA, polimorfismos genéticos, atividade da AchE } \\
\text { e BChE }\end{array}$ \\
\hline Zeljezic et al. ${ }^{52}$ & Tipo de IA, tempo de exposição & Instabilidade genômica: formação de pontes PNP e CRT \\
\hline Lerro et al. ${ }^{53}$ & $\begin{array}{l}\text { Dosagem de metabólitos na urina de } \\
\text { atrazina e de } 2,4 \mathrm{D}\end{array}$ & Estresse oxidativo: níveis urinários de MDA, 8-OHdG, 8-isoPGF \\
\hline Bayrami et al..$^{54}$ & $\begin{array}{l}\text { Avaliação da exposição baseado na } \\
\text { ocupação (agricultores x não agricultores) }\end{array}$ & $\begin{array}{l}\text { Danos oxidativos no DNA, AChE. Alterações no SNC (EEG), } \\
\text { sintomas psicológicos }\end{array}$ \\
\hline Madani et al..$^{55}$ & $\begin{array}{l}\text { Tempo de uso de agrotóxicos, condições } \\
\text { de trabalho, EPI }\end{array}$ & $\begin{array}{l}\text { Alterações bioquímicas, estresse oxidativo e resposta } \\
\text { inflamatória }\end{array}$ \\
\hline Wang et al. ${ }^{56}$ & $\begin{array}{l}\text { Dosagem de metabólitos de clorpirifós na } \\
\text { urina antes e após aplicação }\end{array}$ & Dano oxidativo através da dosagem de $8-\mathrm{OHdG}$ \\
\hline Costa et al. ${ }^{57}$ & $\begin{array}{l}\text { Tempo de exposição aos agrotóxicos, tipo } \\
\text { de agrotóxico utilizado e EPI }\end{array}$ & Estresse oxidativo, polimorfismos genéticos da PON1 \\
\hline Ramírez e Cuenca ${ }^{58}$ & $\begin{array}{l}\text { Tipo de ocupação (trabalhar ou não na } \\
\text { agricultura) }\end{array}$ & Danos no DNA (teste do MN) \\
\hline Pakravan et al. ${ }^{59}$ & $\begin{array}{l}\text { Tipo de OF usado e intervalo entre as } \\
\text { sessões de aplicação }\end{array}$ & $\begin{array}{l}\text { Sinais e sintomas clínicos de intoxicação aguda; níveis de AChE, } \\
\text { TGO, TGP, FA e bilirrubina }\end{array}$ \\
\hline Dasgupta et al. ${ }^{60}$ & $\begin{array}{l}\text { IA, GQ, classificação de toxicidade, } \\
\text { quantidade, número de aplicações, } \\
\text { intensidade e EPI }\end{array}$ & $\begin{array}{l}\text { Questionário: sintomas clínicos de intoxicação aguda, atividade } \\
\text { da AChE }\end{array}$ \\
\hline Mancini et al. ${ }^{61}$ & $\begin{array}{l}\text { Tipo de agrotóxico, quantidade, horas } \\
\text { gastas em uma sessão de aplicação de } \\
\text { agrotóxicos }\end{array}$ & Sinais e sintomas de intoxicação aguda por agrotóxicos \\
\hline Neupane et al. ${ }^{62}$ & $\begin{array}{l}\text { Tipo de agrotóxicos, GQ, IA, uso de EPI, } \\
\text { práticas de higiene após aplicação do } \\
\text { agrotóxico }\end{array}$ & $\begin{array}{l}\text { Questionário para avaliação dos sintomas de intoxicação aguda } \\
\text { e atividade da } \mathrm{AChE}, \mathrm{Hg} \text { e Q }\end{array}$ \\
\hline Oesterlund et al. ${ }^{63}$ & $\begin{array}{l}\text { Tipo de agrotóxicos, conhecimentos, } \\
\text { práticas e atitudes }\end{array}$ & Sintomas de intoxicação aguda autorreferidos \\
\hline Faria et al. ${ }^{64}$ & $\begin{array}{l}\text { Tempo de uso, GQ, atividades realizadas, } \\
\text { EPI }\end{array}$ & $\begin{array}{l}\text { Caso possível e caso provável de exposição ao pesticida At } \\
\text { segundo protocolo de avaliação de atividade de BChE }\end{array}$ \\
\hline $\begin{array}{l}\text { Munoz-Quezada } \\
\text { et al. }{ }^{65}\end{array}$ & $\begin{array}{l}\text { Tipo de IA/GQ, tempo de exposição, EPI, } \\
\text { práticas de higiene, treinamento sobre uso } \\
\text { de agrotóxicos e uso do teste para avaliar } \\
\text { AChE }\end{array}$ & Sinais e sintomas clínicos de intoxicação aguda autorreferidos \\
\hline Khan et al. ${ }^{66}$ & $\begin{array}{l}\text { Uso de pesticidas, quantidade do } \\
\text { IA, toxicidade do IA, práticas e } \\
\text { comportamentos de risco }\end{array}$ & $\begin{array}{l}\text { Morbidade e sintomas clínicos autorreferidos durante a } \\
\text { mistura/ aplicação ou em até } 24 \text { h após contato }\end{array}$ \\
\hline Salameh e Saleh ${ }^{67}$ & $\begin{array}{l}\text { Quatro indicadores: exposição direta; } \\
\text { exposição indireta; não exposto e } \\
\text { exposição cumulativa }\end{array}$ & $\begin{array}{l}\text { Pergunta: "você já foi internado por intoxicação aguda devido } \\
\text { aos agrotóxicos?" }\end{array}$ \\
\hline Souza et al. ${ }^{68}$ & Contato com agrotóxico (sim/não) & Morbidade e sintomas crônicos de saúde autorreferidos \\
\hline
\end{tabular}


Quadro 2 Continuação...

\begin{tabular}{|c|c|c|}
\hline Autor(es) & Avaliação da Exposição (variáveis) & Avaliação do Desfecho \\
\hline Jacobson et al. ${ }^{69}$ & $\begin{array}{l}\text { Tipo de IA, EPI, práticas de limpeza } \\
\text { no trabalho, destino das embalagens, } \\
\text { frequência de aplicação }\end{array}$ & Pergunta aberta: “qual é o seu problema de saúde?" \\
\hline Siqueira et al..$^{70}$ & Aplica ou não agrotóxico & Qualidade de vida: “WHOQOL-bref" \\
\hline Alavanja et al. ${ }^{71}$ & $\begin{array}{l}\text { Tipo de IA, GQ, finalidade de uso e } \\
\text { exposição cumulativa }\end{array}$ & $\begin{array}{l}\text { Linfoma Não Hodking (LNH) e seus subtipos - definidos pelo } \\
\text { Serviço de Vigilância Epidemiológica }\end{array}$ \\
\hline Lerro et al. ${ }^{72}$ & $\begin{array}{l}\text { Aplicou ou misturou agrotóxico durante } \\
\text { toda a vida (nome comercial, IA, GQ, } \\
\text { finalidade de uso) }\end{array}$ & $\begin{array}{l}\text { Câncer- registros hospitalares de câncer (Classificação } \\
\text { Internacional de Doenças para Câncer) }\end{array}$ \\
\hline Engel et al. ${ }^{73}$ & $\begin{array}{l}\text { Tipo de IA, intensidade do uso, dias de } \\
\text { uso, uso de EPI, práticas de manuseio e } \\
\text { aplicação }\end{array}$ & $\begin{array}{l}\text { Câncer de mama - registros hospitalares de câncer (Classificação } \\
\text { Internacional de Doenças para Câncer) }\end{array}$ \\
\hline Lerro et al. ${ }^{74}$ & $\begin{array}{l}\text { Dias de exposição, intensidade de uso } \\
\text { de acetocloro e uso de acetocloro com } \\
\text { atrazina }\end{array}$ & $\begin{array}{l}\text { Câncer- registros hospitalares de câncer (Classificação } \\
\text { Internacional de Doenças para Câncer) }\end{array}$ \\
\hline \multicolumn{3}{|c|}{$\begin{array}{l}\text { AChE: Acetilcolinesterase; BChe: butirilcolinesterase; CRT: comprimento relativo dos telômeros; CT: colesterol total; Cr: creatinina; EEG: eletroencefalo- } \\
\text { grama; EPI: equipamento de proteção individual; ETU: etilenotioureia; FA: fosfatase alcalina; GQ: grupamento químico; GST: glutationa-S-transferase; } \\
\text { HDL: lipoproteína de alta densidade; IA: Ingrediente ativo; OF: organofosforado; OMS: Organização Mundial da Saúde; PNP: pontes nucleoplasmáticas; } \\
\text { TBARS: substâncias reativas com o ácido tiobarbitúricos; TSH: hormônio estimulante da tireóide; T3: triiodotironina total; FT3: triiodotironina livre; } \\
\text { T4: tiroxina total; FT4: tiroxina livre; TG: triglicerídeo; TGO: transaminase glutâmico oxalacética; TGP: transaminase glutâmico pirúvica; TgAb: tireoglobulina; } \\
\text { TPOAb: anticorpos anti-tireoperoxidase U-ureia; US: ultrassonografia; WHO: World health organization; WHOQOL-bref: World Health Organization } \\
\text { Quality of Life }\end{array}$} \\
\hline
\end{tabular}

Apenas seis estudos empregaram biomarcadores de exposição através da detecção de metabólitos de IA nos fluidos corporais ${ }^{27,29,30,41,53,56}$. Outros consideraram: a época da aplicação de agrotóxicos na lavoura - meses de baixa e alta aplicação ${ }^{29,30,42,51,64}$; fases de cultivo - preparo da terra, plantio, acompanhamento da lavoura, colheita e período de entre safra) ${ }^{53}$ e antes e após aplicação ${ }^{56}$.

Quanto aos desfechos, identificaram-se três grandes grupos de agravos à saúde:

I) Agravos crônicos - doenças neurológicas $^{16-21,54,68}$; doenças e transtornos mentais $22,23,24,54,68$; câncer ${ }^{25-28,68,71-74}$; doenças da tireoide e distúrbios hormonais/metabóli$\cos ^{29-31,68}$; doenças renais ${ }^{32,68}$; doenças respiratórias $^{33,68}$; alterações auditivas ${ }^{34,35}$; doença autoimune $^{36}$;

II) Condições subclínicas ${ }^{20,29,37-40,42-45,48,50,52-55,62}$ : alterações bioquímicas, danos genéticos, estresse oxidativo;

III) Sinais e sintomas de intoxicação aguda, queixas de saúde 60-67,69,70. $^{6}$.

Dentre os métodos de avaliação dos desfechos (Quadro 2), o uso de exames clínicos ou instrumentos já validados ocorreram em 21 estudos $^{16-18,20-23,25-28,30,32,33,36,64,68,71-74}$, a morbidade, sinais e sintomas autorreferidos em 14 estu$\operatorname{dos}^{24,33,37,39,41,60,62,63,65-70}$ e o uso de biomarcadores de efeito em 23 estudos $20,27,29,30,37,39,40,42-45,47,48,50-55,60,62,64$.

Com relação à amostragem, a maioria dos estudos transversais utilizou amostragem por conveniência ${ }^{19,23,30,34,38,40,45,47,48,54,61,68,70}$, sete estudos empregaram amostragem probabilística ${ }^{22,24,29,35,62,63,66}$, três não informaram o tipo de amostragem ${ }^{20,24,65}$ e em dois estudos ${ }^{55,69}$ foi realizado um censo de todas as propriedades familiares, com seleção aleatória de um indivíduo de cada propriedade, para a amostra. Em alguns estudos, as amostras de domicílios foram calculadas segundo parâmetros estatísticos, mas, posteriormente, não houve seleção probabilística dos indivíduos ${ }^{44,64}$. No estudo de Hongsibsong et al. ${ }^{41}$ empregou-se amostragem por conglomerados (vilas), porém não há informações sobre a seleção dos indivíduos. No estudo de Dasgupta et al. ${ }^{60}$ a amostragem foi estratificada por regiões de cultivo.

As análises estatísticas variaram em função do tipo de estudo. Nos estudos transversais empregaram-se testes estatísticos mais simples (teste de diferença de proporções, de diferença de médias etc. $)^{19,20,35,38,40,41,44,45,48,64,68,70}$ e modelos multivaria$\operatorname{dos}^{22-24,29,30,34,47,52,54,55,60-63,65-67,69}$. Nos estudos de 
coorte e caso-controle, análises multivariadas ocorreram em 16 pesquisas ${ }^{16,21,25,27,28,31-33,37,42,50,51,53,71,72,74}$. Tais análises foram ajustadas para as variáveis de confusão: idade $16,17,19,21,23,27,28,30,31,32,34,36,37,42,50,52,53,66,67,71-$ 74 sexo $^{19,27,28,37,42,52,67}$, escolaridade ${ }^{19,67,72,74}$, consumo de tabaco $27,28,30,31,36,37,42,50,52,67,72,74$, consumo de álcool ${ }^{37,42,50,52,72,74}$, consumo de café ${ }^{16,27}$, Índice de Massa Corpórea (IMC) ${ }^{21,31,37,72}$, exposição solar $^{42,50}$, níveis sanguíneos de folato e vitamina $\mathrm{B} 12^{50}$, renda ${ }^{66,67}$, raça ${ }^{71-73}$, conhecimento sobre pesticidas $^{66}$, local/estado de residência ${ }^{36,71-74}$, eventos estressantes na vida ${ }^{23}$, dor ${ }^{21,23}$, capacidade física funcional $^{23}$, história prévia de doença da tireoide ${ }^{30}$, história familiar de câncer ${ }^{72,74}$, uso de herbicidas ${ }^{71}$ ou agrotóxicos $^{74}$, tipo de equipamento de aplicação ${ }^{74}$, uso de contraceptivo oral ${ }^{72}$, idade da menopausa ${ }^{72,73}$, uso de dominossanitários ${ }^{72}$ e idade ao nascimento/ paridade combinada ${ }^{73}$. Alguns pesquisadores também consideraram em seus modelos outras variáveis ${ }^{31,67}$. Em dois estudos, não houve diferenças significativas entre as odds ratio (ORs) brutas e ajustadas, portanto, os resultados referem-se aos valores brutos ${ }^{17,25}$.

O Quadro 3 apresenta os principais achados sucblínicos e o Quadro 4 os efeitos crônicos e agudos encontrados. A seguir serão descritos apenas os resultados que apresentaram associações estatisticamente significativas. Quanto aos achados subclínicos, associações positivas e significativas entre exposição aos agrotóxicos e dano oxidativo no DNA ocorreram em quatro estudos ${ }^{40,53-56}$. Também foram observadas associações entre ocupação (agricultor) ${ }^{44,64}$ e dias de aplicação de fungicidas ${ }^{42}$ com danos no DNA medidos através do ensaio cometa. Tumer et al. ${ }^{47}$ demonstraram que o tempo de trabalho agrícola associou-se com a frequência de micronúcleos (MN) no DNA. Resultados semelhantes foram encontrados em três estudos ${ }^{40,44,45}$. A presença de micronúcleos no DNA indicam danos permanentes no código genético que ocorrem durante a exposição a contaminantes químicos, sendo um dos mecanismos propostos da carcinogênese ${ }^{75}$.

Quadro 3 Principais efeitos subclínicos ocasionados por agrotóxicos identificados nos estudos selecionados

\begin{tabular}{|c|c|}
\hline Autor(es) & Principais resultados \\
\hline García-García et al. ${ }^{37}$ & $\begin{array}{l}\text { As médias de glicemia, } C T, C r \text {, FA foram significativamente maiores no período de alta exposição do que no } \\
\text { período de baixa exposição. Os expostos apresentaram menores níveis de glicemia, } C T, T G, C r, F A \text { e BChE do } \\
\text { que os controles e maiores níveis de AChE e pressão diastólica do que os controles. }\end{array}$ \\
\hline Aroonvilairat et al. ${ }^{38}$ & $\begin{array}{l}\text { A atividade da AChE foi significativamente menor em homens e mulheres expostos a OF e carbamatos em } \\
\text { comparação aos controles. Os níveis séricos de IgE foram significativamente maiores entre produtores de } \\
\text { orquídeas em comparação aos controles. A concentração total de linfócitos B e total de células CD19+ } \\
\text { foi menor entre expostos do que em controles. As concentrações de Cre U plasmática não diferiram } \\
\text { significativamente entre os dois grupos. As concentrações plasmáticas de proteína total e albumina foram } \\
\text { significativamente menores nos produtores de orquídeas do que nos controles. Não houve diferenças } \\
\text { significativas entre os grupos quanto aos parâmetros hematológicos e níveis de lisozima. }\end{array}$ \\
\hline Rocha et al. ${ }^{39}$ & $\begin{array}{l}\text { Para todos os metais analisados, os expostos apresentaram níveis de } 2 \text { a } 4 \text { vezes maiores do que os } \\
\text { controles nas } 1^{\mathrm{a}} \text { e } 2^{\mathrm{a}} \text { visitas. Na } 3^{\mathrm{a}} \text { visita, as concentrações de metais foram de } 1,5 \text { a } 2 \text { vezes maiores nos } \\
\text { expostos do que nos controles. }\end{array}$ \\
\hline Alves et al. ${ }^{40}$ & $\begin{array}{l}\text { Os plantadores de tabaco apresentaram danos no DNA significativamente maiores do que os controles } \\
(\mathrm{p}<0,05) \text {. A presença de polimorfismos genéticos da PON1 associou-se positivamente com frequência de MN } \\
(\mathrm{p}<0,01) \text {. No grupo exposto a atividade da SOD foi maior que nos controles }(\mathrm{p}<0,001) \text {. Os plantadores de } \\
\text { tabaco apresentaram maiores concentrações de monócitos e neutrófilos do que os controles. Os expostos } \\
\text { tiveram maiores concentrações de } \mathrm{Zn}, \mathrm{Mg} \text { e Al no sangue. }\end{array}$ \\
\hline Hongsibsong et al. ${ }^{41}$ & $\begin{array}{l}\text { Agricultores com falta de ar tiveram níveis significativamente maiores de } \Sigma \text { DAP em comparação aos que } \\
\text { não referiram sintoma. Os agricultores que referiram falta de ar e dor no peito apresentaram maiores danos } \\
\text { no DNA (maior comprimento da cauda e maior tempo de cauda) em comparação aos que não referiram } \\
\text { os sintomas. Falta de ar, dor no peito, garganta seca, dormência, dor de cabeça, tontura e irritação ocular } \\
\text { foram estatisticamente associados à menor atividade de } A C h E \text {. Houve diferenças significativas na RP de } \\
\text { entorpecimento e fraqueza muscular entre os grupos ( } R P=3,45 \text {; IC95\%: } 1,125-10,552, p<0,05 \text { e } \\
\text { RP }=3,79 \text {; IC95\%: } 1,370-10,466, p<0,01 \text {, respectivamente). }\end{array}$ \\
\hline Lebailly et al. ${ }^{42}$ & $\begin{array}{l}\text { A análise longitudinal (períodos P0 e P4) revelou que, entre os expostos, o dano nos linfócitos B e T } \\
\text { foi significativamente maior em P4 do que em P0 }(p=0,02) \text {. O dano no DNA dos linfócitos B e T foram } \\
\text { significativamente maiores nos agricultores do que nos controles em P4 ( } p=0,003 \text { e } p=0,001 \text { para } \\
\text { linfócitos B e T, respectivamente). Entre os dois períodos de tempo estudados, houve uma tendência de } \\
\text { efeito do número de dias de tratamentos com fungicidas }\left(r^{2}=0,43 ; p=0,11\right) \text { sobre o dano do DNA de } \\
\text { linfócitos T. Isso não ocorreu para herbicidas e inseticidas. }\end{array}$ \\
\hline
\end{tabular}


Quadro 3 Continuação...

\begin{tabular}{|c|c|}
\hline Autor(es) & Principais resultados \\
\hline $\begin{array}{l}\text { De Oliveira e } \\
\text { Ehrhardt }\end{array}$ & $\begin{array}{l}\text { Não houve diferenças significativas nas concentrações de AChE e de BChE antes e após a aplicação de } \\
\text { agrotóxico }(p>0,05) \text {. }\end{array}$ \\
\hline Rosales $^{44}$ & $\begin{array}{l}\text { Os expostos tiveram níveis significativamente menores de BChE e maiores danos no DNA (teste do MN e } \\
\text { ensaio cometa) em comparação aos controles. Não houve diferenças significativas quanto à frequência de } \\
\text { aberrações cromossômicas entre expostos e não expostos ( } p>0,05 \text { para todos os parâmetros). }\end{array}$ \\
\hline Carbajal-López et al. ${ }^{45}$ & $\begin{array}{l}\text { Os expostos apresentaram maiores danos no DNA para todos os parâmetros avaliados em comparação aos } \\
\text { controles. Não houve correlação entre danos no DNA e tempo de exposição. }\end{array}$ \\
\hline Simoniello et al. ${ }^{46}$ & $\begin{array}{l}\text { Houve redução de } A C h E(p<0,001) \text { em expostos diretos e indiretos; aumento nos níveis de TBARS } \\
(p<0,001) \text { nos expostos diretos; redução significativa de CAT }(p<0,01) \text { e aumento do IDER }(p<0,001) \text { em } \\
\text { ambos os grupos. }\end{array}$ \\
\hline Tumer et al. ${ }^{47}$ & $\begin{array}{l}\text { Os expostos tiveram } 3,4 \text { vezes maior dano no DNA (frequência } M N) \text { do que os controles }(p<0,001) \text {. No } \\
\text { modelo multivariado, a frequência de } M N \text { foi associada positivamente com anos de trabalho agrícola } \\
(B=6,225 ; E P=0,568 ; p=0,032) \text { e genótipo nulo GSTM1 }(B=1,001 ; E P=0,520 ; p=0,017) \text {. }\end{array}$ \\
\hline Saad-Hussein et al. ${ }^{48}$ & $\begin{array}{l}\text { Danos no DNA foram maiores nos trabalhadores em comparação com controles }(\mathrm{p}<0,01) \text {. Trabalhadores } \\
\text { expostos com os genótipos GSTP1 Ile-lle e XRCC1399 Arg-Arg mostraram dano no DNA significativamente } \\
\text { maior em comparação com outros alelos. }\end{array}$ \\
\hline Mackness et al. ${ }^{49}$ & $\begin{array}{l}\text { Os criadores de ovelha que relataram doenças crônicas devido à exposição a organofosforados têm uma proporção } \\
\text { maior do polimorfismo PON1-192R associado a taxas mais baixas de hidrólise do inseticida diazinona }\end{array}$ \\
\hline Rusieki et al. ${ }^{50}$ & $\begin{array}{l}\text { Eventos de alta exposição a agrotóxicos foram associados significativamente com a metilação de DNA na } \\
\text { região promotora da GSTp1 e em alguns subgrupos de promotores de DNAm: MGMT e LINE-1. }\end{array}$ \\
\hline Gómez-Martín et al. ${ }^{51}$ & $\begin{array}{l}\text { Os níveis de N7-MedG foram significativamente maiores nos períodos de alta exposição em comparação aos de } \\
\text { baixa exposição. Polimorfismos genéticos da PON1 e da GST associaram-se com a metilação do DNA (N7-MedG). }\end{array}$ \\
\hline Zeljezic et al. ${ }^{52}$ & $\begin{array}{l}\text { Não houve diferenças significativas no comprimento dos telômeros entre expostos e controles }(\mathrm{p}>0,05) \text {. } \\
\text { O número de PNP nos expostos foi significativamente maior do que nos controles. Não houve associação } \\
\text { positiva entre a formação de PNP e encurtamento dos telômeros. }\end{array}$ \\
\hline Lerro et al..$^{53}$ & $\begin{array}{l}\text { Níveis elevados de 2,4-D na urina associaram-se positiva e significativamente com aumentos de 8-OHdG e } \\
\text { 8-isoPGF. Não houve associação significativa entre 2,4-D e MDA ou mercapturato de atrazina . }\end{array}$ \\
\hline Bayrami et al. ${ }^{54}$ & $\begin{array}{l}\text { Os níveis médios de SOD e LPO foram maiores nos agricultores do que nos controles }(p=0,01) \text {. A } \\
\text { concentração de TAC e AChE foi menor nos agricultores do que nos controles }(p=0,001) \text {. Não houve } \\
\text { diferenças significativas entre os agricultores e controles quanto aos níveis de TTM, 8-OH-dG, e CAT. }\end{array}$ \\
\hline Madani et al. ${ }^{55}$ & $\begin{array}{l}\text { Associação positiva e significativa entre a duração da exposição aos agrotóxicos e níveis de glicose, TG, TGO, } \\
\text { TG, proteína } C \text { reativa, protrombia e fibrinogênio }(p<0,05) \text {. Houve associação inversa significativa entre a } \\
\text { duração da exposição aos agrotóxicos e marcadores antioxidantes }(p<0,01) \text { e positiva com os marcadores } \\
\text { oxidativos }(p<0,04) \text {. }\end{array}$ \\
\hline Wang et al..$^{56}$ & $\begin{array}{l}\text { Os agricultores apresentaram maiores níveis basais urinários de metabólitos de clorpirifós do que os } \\
\text { controles. Houve aumento significativo da excreção urinária de 8-OHdG no primeiro dia após aplicação, } \\
\text { comparada aos três dias antes da aplicação, retornando aos níveis normais após o terceiro dia de aplicação. }\end{array}$ \\
\hline Costa et al..$^{57}$ & $\begin{array}{l}\text { A presença de polimorfismos genéticos da PON1 associou-se significativamente a marcadores de estresse } \\
\text { oxidativo (AGE e AOPP). }\end{array}$ \\
\hline Ramírez e Cuenca ${ }^{58}$ & $\begin{array}{l}\text { Todas as mulheres expostas a agrotóxicos e que tiveram abortos espontâneos ou natimortos tiveram chances } \\
1,45 \text { vezes maior de ter danos no DNA (presença de } \mathrm{MN} \text { ) quando comparadas às mulheres não expostas. }\end{array}$ \\
\hline Pakravan et al. ${ }^{59}$ & $\begin{array}{l}\text { Houve diferenças significativas entre os níveis de AChE antes da exposição e durante, com redução de } 54 \% \\
\text { de sua atividade; e entre durante a exposição e após a exposição ( } x=4.155 \pm 275 \text { vs } x=6.615 \pm 392 ; \\
\text { p < 0,05). Os níveis de AChE no t0 (antes da exposição) e no t3 (oito semanas após exposição) não diferiram } \\
\text { estatisticamente. }\end{array}$ \\
\hline
\end{tabular}

AChE: Acetilcolinesterase; AGE: produtos finais da glicação avançada; Al: alumínio; AOPP produtos de oxidação protéica; BChE butirilcolinesterase; CAT: Catalases; CRT: comprimento relativo dos telômeros; CT: colesterol total; Cr: creatinina; DAP: dialqui-fosfato; 2,4D: ácido 2,4 diclofenoxiacético; EEG: eletroencefalograma; EPI: equipamento de proteção individual; ETU: etilenotioureia; FA: fosfatase alcalina; GST: glutationa-S-transferase; 8-isoPGF: 8-isso-prostaglandina F; LPO: peroxidação lipídica; Mg: magnésio; MN: Micronúcleo; MDA: malondialdeído; N7: MedG-N7-metildeoxiguanosina; OF: organofosforado; 8OH-Dg: 8-oxo-2'-desoxiguanosina; PNP: pontes nucleoplasmáticas; PON1: paraoxonase1; SOD: superóxido dismutase; TAC: capacidade antioxidante total; TBARS: substâncias reativas com o ácido tiobarbitúricos; TG: triglicerídeo; TGO: transaminase glutâmico oxalacética, TGP: transaminase glutâmico pirúvica; TTM: moléculas de tiol totais; U: ureia; Zn: zinco 
Quadro 4 Principais efeitos crônicos e agudos ocasionados por agrotóxicos identificados nos estudos selecionados

\begin{tabular}{|c|c|}
\hline Autor(es) & Principais resultados \\
\hline \multicolumn{2}{|c|}{ DOENÇAS NEUROLÓGICAS } \\
\hline Moisan et al. ${ }^{16}$ & $\begin{array}{l}\text { Associação significativa entre intensidade da exposição e } D P(O R=2,04, \text { IC95\%: } 1,03 \text { - 4,05) e entre duração da } \\
\text { exposição e DP }(\mathrm{OR}=2,28, \mathrm{IC} 95 \%: 1,16 \text { - 4,50), para inseticidas e fungicidas, respectivamente. }\end{array}$ \\
\hline Nielsen et al. ${ }^{17}$ & $\begin{array}{l}\text { Não houve associação significativa entre não uso de EPI, a reentrada frequente de áreas tratadas com agrotóxicos e } \\
\text { sintomas/sinais de PS. Residir ou comprar uma fazenda foram associados significativamente com sinais de PS. }\end{array}$ \\
\hline $\begin{array}{l}\text { Nguyen } \\
\text { et al. }{ }^{18}\end{array}$ & $\begin{array}{l}\text { Trabalhadores agrícolas tiveram piores escores na capacidade de aprendizagem ( } p=0,01) \text {, memória de curto prazo } \\
(p=0,01) \text { e capacidade de codificação perceptual }(p=0,04) \text { em comparação aos não trabalhadores agrícolas. }\end{array}$ \\
\hline Zhang et al. ${ }^{19}$ & $\begin{array}{l}\text { Os casos apresentaram escores estatisticamente superiores aos controles para raiva/hostilidade, depressão/ } \\
\text { abatimento, tensão/ansiedade e menores para vigor/atividade. }\end{array}$ \\
\hline Jamal et al. ${ }^{20}$ & $\begin{array}{l}\text { As pontuaç̃ões de ansiedade/insônia e depressão severa foram maiores em expostos do que não expostos. } \\
\text { A disfunça social foi significativamente menor entre os expostos do que em controles. Nos parâmetros de } \\
\text { comprometimento de função neurocognitiva, os agricultores expostos apresentaram os menores valores quando } \\
\text { comparados aos controles. Houve diferenças significativas entre aplicadores e controles para todos os parâmetros } \\
\text { bioquímicos avaliados, com exceção de TGP e TG. }\end{array}$ \\
\hline $\begin{array}{l}\text { Sunwook } \\
\text { et al. }{ }^{21}\end{array}$ & $\begin{array}{l}\text { A exposição aos agrotóxicos ao longo da vida associou-se inversamente com o índice de complexidade de equilíbrio } \\
\text { postural (agricultores expostos apresentaram piores desempenhos no equilíbrio postural). }\end{array}$ \\
\hline \multicolumn{2}{|c|}{ DOENÇAS E TRANSTORNOS MENTAIS } \\
\hline $\begin{array}{l}\text { Campos } \\
\text { et al. } 22\end{array}$ & $\begin{array}{l}\text { Maior chance de depressão entre os que têm contato com agrotóxicos antes dos } 15 \text { anos. Maior chance de depressão para } \\
\text { os expostos a piretróides, álcool alifático, dinitroanilina e sulfoniluréia. Houve associação positiva entre intoxicação por } \\
\text { agrotóxicos e TPM e depressão. Houve associação positiva entre SRQ- } 20 \geq 8 \text { e exposição a álcool alifático. }\end{array}$ \\
\hline $\begin{array}{l}\text { Harrison e } \\
\text { Ross }^{23}\end{array}$ & $\begin{array}{l}\text { A exposição à OF aumentou a chance de diagnóstico de ansiedade em 13,44 vezes, mas não para diagnóstico de } \\
\text { depressão. Houve associação significativa entre sintomas autorreferidos de depressão/ansiedade e exposição a OF. }\end{array}$ \\
\hline Kim et al. ${ }^{24}$ & $\begin{array}{l}\text { Os casos moderados/severos de intoxicação aguda associaram-se com tentativa de suicídio, com tempo de } \\
\text { hospitalização decorrente de intoxicação por pesticida e ocorrência de episódios de intoxicação aguda. Não houve } \\
\text { associação positiva entre ocorrência de intoxicação aguda mais de uma vez e tentativa de suicídio mais de uma vez. }\end{array}$ \\
\hline \multicolumn{2}{|l|}{ CÂNCER } \\
\hline $\begin{array}{l}\text { Lemarchand } \\
\text { et al. }{ }^{25}\end{array}$ & $\begin{array}{l}\text { A exposição aos agrotóxicos na pecuária aumenta o risco de câncer de próstata. O uso de agrotóxico por cultura } \\
\text { (trigo/cevada) aumenta o risco de câncer de próstata em } 1,17 \text { vezes. O RR para aplicação de agrotóxicos em árvores } \\
\text { frutíferas com terreno maior ou igual a } 25 \text { hectares foi de } 2,28 \text {. A exposição combinada a pesticidas para as culturas: } \\
\text { cevada/trigo e batata associou-se com risco de câncer de pulmão. }\end{array}$ \\
\hline Bonner et al. ${ }^{26}$ & $\begin{array}{l}\text { Tempo de uso de clorimuron etil e de maconzeb/maneb aumenta o risco de câncer de pulmão. A intensidade de uso } \\
\text { de maconzeb/maneb eleva o risco de câncer de pulmão ( } R R=3,21 ; \text { IC95\%: } 1,74-5,91) \text {. }\end{array}$ \\
\hline Boada et al. ${ }^{27}$ & $\begin{array}{l}\text { A exposição aos OC associou-se inversamente à chance de câncer de bexiga. Esta associação não ocorreu na presença } \\
\text { de polimorfismo genético da enzima GST (GST-T1 nulo): (OR =0,930; IC95\%: 0,824-1,050; } p=0,242) \text {. }\end{array}$ \\
\hline $\begin{array}{l}\text { Boulanger } \\
\text { et al. }{ }^{28}\end{array}$ & A exposição a agrotóxicos não foi estatisticamente associada ao risco de câncer de bexiga. \\
\hline $\begin{array}{l}\text { Alavanja } \\
\text { et al. }^{71}\end{array}$ & $\begin{array}{l}\text { O RR para LNH foi alto para a maior categoria de exposição ao DDT e lindano. Nas análises de subtipo, os terbufos } \\
\text { e o DDT foram associados ao linfoma de pequenas células/linfocitose crônica leucemia/linfoma marginal de células; } \\
\text { lindano e diazinon com linfoma folicular e permetrina com MM. }\end{array}$ \\
\hline Lerro et al. ${ }^{72}$ & $\begin{array}{l}\text { Todos os OP foram associados a um risco elevado de câncer de mama ( } R R=1,20 ; \text { IC95\%: } 1,01-1,43) \text {. Malation } \\
\text { associou-se com aumento do risco de câncer de tireoide }(R R=2,04 ; \text { IC95\%: } 1,14-3,63) \text { e diminuição do risco } \\
\text { de Linfoma não-Hodgkin ( } R R=0,64 ; \text { IC95\%: } 0,41-0,99) \text {. O uso de diazinon foi associado com câncer de ovário } \\
(\operatorname{RR}=1,87, I C 95 \%: 1,02-3,43) \text {. }\end{array}$ \\
\hline Engel et al. ${ }^{73}$ & $\begin{array}{l}\text { O RR para câncer de mama entre as mulheres que já relataram ter usado inseticidas em algum momento da vida foi } \\
\text { de } 1,4 \text { (IC95\%: } 1,0-2,0) \text { para clorpirifós e } 1,5 \text { para tebufós (IC95\%: } 1,0-2,1) \text {. O uso de forato pelas mulheres e seus } \\
\text { maridos aumentou o RR de câncer para 2,0 (IC95\%: } 1,0-4,1) \text {. }\end{array}$ \\
\hline Lerro et al. ${ }^{74}$ & $\begin{array}{l}\text { Risco aumentado de câncer de pulmão foi observado entre os usuários de acetocloro (RR = 1,74; IC95\%: } 1,07-2,84) \\
\text { em comparação aos não usuários, e entre os indivíduos que relataram o uso de misturas de produtos acetocloro/ } \\
\text { atrazina ( } R R=2,33 \text {; IC95\%: } 1,30 \text { - 4,17), comparado aos não usuários de acetocloro. O risco de câncer colorretal } \\
\text { foi significativamente elevado entre a categoria mais alta de usuários de acetocloro ( } R R=1,75 ; \text { IC95\%: } 1,08-2,83) \\
\text { em comparação com os não usuários. Não houve associações significativas para melanoma (RR = 1,61; IC95\%: } \\
0,98 \text { - 2,66) e câncer de pâncreas ( } R R=2,36 \text {; IC95\%: } 0,98-5,65) \text {. }\end{array}$ \\
\hline
\end{tabular}


Quadro 4 Continuação...

\begin{tabular}{|c|c|}
\hline Autor(es) & Principais resultados \\
\hline \multicolumn{2}{|c|}{ DOENÇAS DA TIREÓIDE E DISTÚRBIOS HORMONAIS OU METABÓLICOS } \\
\hline Piccoli et al. ${ }^{29}$ & $\begin{array}{l}\text { Em geral, as associações entre níveis de OC no sangue e de hormônios tireoidianos foram fracas e inconsistentes; não } \\
\text { houve associação significativa entre atividade das colinesterases e níveis de hormônios tireoidianos. }\end{array}$ \\
\hline Medda et al. ${ }^{30}$ & $\begin{array}{l}\text { A exposição ocupacional ao maconzeb etá associada à disfunção da tireoide, sendo mais pronunciada em } \\
\text { trabalhadores expostos residentes em uma área com deficiência leve a moderada de iodo (Chianti) em comparação a } \\
\text { trabalhadores residentes em uma área coberta por um programa de profilaxia iodada de longa duração (Bolzano). }\end{array}$ \\
\hline $\begin{array}{l}\text { La Verda } \\
\text { et al. }{ }^{31}\end{array}$ & $\begin{array}{l}\text { Quanto maior a exposição à triazina e atrazina, maior o IMC. Esse efeito foi mais pronunciado entre os aplicadores } \\
\text { residentes de lowa. Estas associações não foram observadas na Carolina do Norte. }\end{array}$ \\
\hline \multicolumn{2}{|l|}{ DOENÇA RENAL } \\
\hline Lebov et al. ${ }^{32}$ & $\begin{array}{l}\text { Risco maior de DRET entre as esposas que aplicavam agrotóxicos em geral para a categoria de maior dias de uso } \\
(>507,5 \text { dias; } R R=4 ; 22 ; \text { IC95\%: } 1,26-14,2) \text {. O uso de chlorimuron-ethyl entre as esposas e risco de DRET foi alto } \\
(\mathrm{RR}=4,03 ; \mathrm{IC} 95 \%: 1,30-12,51) \text {. Entre as esposas que nunca aplicaram pesticidas, a DRET esteve associada ao uso de } \\
\text { paraquat ( } R R=1,99 ; \mathrm{IC} 95 \%: 1,14-3,47) \text { e butilato }(\mathrm{RR}=1,71 ; \mathrm{IC} 95 \%: 1,00-2,95) \text { pelo marido. }\end{array}$ \\
\hline \multicolumn{2}{|c|}{ DOENÇA RESPIRATÓRIA } \\
\hline Hoppin et al. ${ }^{33}$ & $\begin{array}{l}\text { Houve associação positiva e significativa de dose-resposta (dias de uso de agrotóxicos e chance de sibilo alérgico e } \\
\text { não alérgico) para 2,4D, atrazina, glifosato, carbaril, malation, permetrina e warfarina. }\end{array}$ \\
\hline \multicolumn{2}{|c|}{ ALTERAÇÕES AUDITIVAS } \\
\hline Bazilio et al. ${ }^{34}$ & $\begin{array}{l}\text { Quanto maior o índice de exposição, maior a chance de alterações auditivas em ambos os ouvidos observadas no TPD } \\
\text { e no teste "gaps in noise". }\end{array}$ \\
\hline De Sena ${ }^{35}$ & $\begin{array}{l}\text { Quanto maior o grau de toxicidade do agrotóxico, maior a prevalência de perda auditiva. Os expostos a agrotóxicos } \\
\text { tiveram escores de qualidade de vida significativamente inferiores em todos os domínios, exceto para capacidade } \\
\text { funcional (não houve diferenças significativas entre expostos e não expostos a agrotóxicos). }\end{array}$ \\
\hline \multicolumn{2}{|c|}{ DOENÇA AUTOIMUNE } \\
\hline Parks et al. ${ }^{36}$ & $\begin{array}{l}\text { Dos } 15 \text { pesticidas examinados, maneb / mancozeb }(O R=3,3 ; \mathrm{IC} 95 \%: 1,5-7,1) \text { e glifosato }(O R=1,4 ; \mathrm{IC} 95 \%: 1,0-2,1) \\
\text { foram associados a casos incidentes de AR. }\end{array}$ \\
\hline
\end{tabular}

Siqueira Trabalhadores que aplicam agrotóxicos apresentaram maior frequência de queixas relacionadas a dores na coluna em et al. ${ }^{70} \quad$ comparação àqueles que não aplicam. Houve diferenças significativas para os domínios físico, psicológico e social da escala WHOQOL-Bref entre os grupos de trabalhadores, sendo as piores médias encontradas nos aplicadores de agrotóxicos.

Oesterlund Houve associação positiva entre toxicidade do agrotóxico e intoxicação aguda. Ser mulher é um fator de proteção et al. ${ }^{63}$ para intoxicação aguda em todas as classes de toxicidade de agrotóxicos. Soprar ou sugar o bico do pulverizador aumenta a chance sintomas de intoxicação aguda por agrotóxicos (OR bruto = 2,5; IC95\%: 1,4-4,3).

Dasgupta A análise de regressão revelou: a cada 1\% de aumento na quantidade de agrotóxico utilizada, diminui 9,8\% a chance et al. ${ }^{60}$ de intoxicação aguda; a cada $1 \%$ de aumento no uso de agrotóxicos classificados pela OMS nas categorias WHO la e WHO Ib, aumenta a probabilidade de intoxicação em 3,9\%; o uso de medidas protetivas diminui a probabilidade de intoxicação em $44,3 \%$.

Salameh $\quad 0$ modelo ajustado revelou associação positiva entre exposição cumulativa de agrotóxicos e sintomas gastrintestinais et al. ${ }^{67} \quad(O R=2,28 ;$ IC95\%: $1,03-5,05 ; p=0,04)$, imunoalérgicos (OR = 3,63; IC95\%: 1,93-6,85; $\left.p=0,0001\right)$; anorexia $(O R=4,98$; IC95\%: 1,33 - 18,55; $p=0,04)$, infecções do trato respiratório superior $(\mathrm{OR}=16,61 ;$ IC95\%: 3,52 - 78,51; $p=0,04)$, epistaxe $(O R=6,30 ;$ IC95\%: $2,01-19,71 ; p=0,04)$ e internação por intoxicação aguda $(O R=4,99$; IC95\%: $1,59-15,64 ; p=0,04)$.

Faria et al. ${ }^{64}$ Maior escolaridade revelou efeito protetor contra a ocorrência de intoxicação aguda. A frequência de uso de agrotóxicos, o uso de mangueira com "caneta" de pulverização e a ausência de máscaras associou-se positivamente com casos possíveis de intoxicação aguda.

Neupane Maior chance de intoxicação aguda em agricultores expostos a agrotóxicos em comparação aos controles para as et al. ${ }^{62}$ seguintes manifestações clínicas: náusea, visão turva, tontura, fraqueza muscular, dor de cabeça, exaustão; ausência de coordenação, suor excessivo, boca seca.

Jacobson Houve associação positiva entre: capina com herbicida e problemas de saúde $(O R=3,67 ; p=0,047)$; aplicação et al. ${ }^{69} \quad$ semanal de agrotóxicos e problemas de saúde quando a capina é realizada com herbicida $(\mathrm{OR}=6,89 ; \mathrm{p}=0,047)$; equipamento de proteção e problemas de saúde, quando a capina é feita com herbicida ( $O R=3,57 ; p=0,049)$. 
Quadro 4 Continuação...

\begin{tabular}{ll}
\hline Autor(es) & \multicolumn{1}{c}{ Principais resultados } \\
\hline $\begin{array}{l}\text { Mancini } \\
\text { et al. }{ }^{61}\end{array}$ & $\begin{array}{l}\text { As variáveis toxicidade de agrotóxico e tempo de exposição associou-se positiva e significativamente ao índice } \\
\text { de severidade de intoxicação e, a educação formal associou-se negativamente. Com relação ao somatório de } \\
\text { sinais e sintomas de intoxicação aguda, as variáveis toxicidade, tempo de exposição associaram-se positiva e } \\
\text { significativamente e as variáveis educação formal e profissão associaram-se negativamente. }\end{array}$ \\
$\begin{array}{l}\text { Muñoz- } \\
\text { Quezada } \\
\text { et al. }{ }^{65}\end{array}$ & $\begin{array}{l}\text { O uso de máscaras e menor idade (<47 anos) associaram-se negativamente com sinais/sintomas de intoxicação } \\
\text { aguda. O tempo de exposição a agrotóxicos teve associação positiva com sinais/sintomas de intoxicação aguda. }\end{array}$ \\
Khan et al. $^{66}$ & $\begin{array}{l}\text { Aumentos significativos de efeitos na saúde com a quantidade de agrotóxicos, uso de agrotóxicos altamente tóxicos } \\
\text { (toxicidade classe la e lb) e o distrito de residência. O uso de EPI mostrou-se inversamente associado ao risco de } \\
\text { agravos à saúde. }\end{array}$ \\
\hline
\end{tabular}

AR: Artrite reumatoide; DP: Doença de Parkinson; 2,4D: ácido diclorofenoxiacético; DDT: diclorodifeniltricloroetano; DRET: Doença renal em estágio terminal; EPI: Equipamento de proteção individual; GST: Glutationa-S-transferase; IMC: Índice de massa corporal; LNH: Linfoma Não Hodgkin; MM: Mieloma múltiplo. PS: Parkinsonismo; OF: Organofosforado; OC: Organoclorado; OMS: Organização Mundial de Saúde; OR: Odds ratio (Razão de chances); RR: risco relativo; SRQ-20: Self reporting questionnaire; TG: Triglicerídeos; TGP: Transaminase glutâmico pirúvica; TPD: Teste padrão de duração; TPM: Transtorno psiquiátrico menor; WHO: World Health Organization.

Observou-se que a ocorrência de polimorfismos genéticos de enzimas de detoxificação de contaminantes químicos aumenta o dano ao DNA em agricultores expostos a agrotóxicos quando comparados aos controles ${ }^{40,47,48}$ e potencializa a associação entre exposição aos agrotóxicos e metilação do DNA em agricultores $^{50,51}$. Pesquisas científicas têm evidenciado que mecanismos de metilação no DNA parecem estar envolvidos no desenvolvimento de câncer de próstata ${ }^{75}$ (Quadro 3).

O estudo da coorte francesa de agricultores (AGRICAN) revelou associações positivas entre exposição a agrotóxicos e risco de câncer de próstata ${ }^{25}$ (Quadro 4). Os estudos da coorte estadounidense Agriculture Health Study revelaram maior risco de câncer de pulmão em aplicadores para os IA clorimuron, maconzeb/maneb ${ }^{26}$, acetocloro ${ }^{74}$ e misturas de acetocloro com atrazina ${ }^{74}$; risco elevado de Linfoma Não-Hodgkin (LNH) e seus subtipos para determinados $\mathrm{IA}^{71}$; risco relativo alto de câncer de colorretal para acetocloro ${ }^{74}$; maior risco de câncer em geral em mulheres expostas a organofosforados $(\mathrm{OF})^{72}$; risco elevado de câncer da tireoide entre expostas ao malation e de câncer de ovário entre expostas à diazinona $^{72}$; risco aumentado de câncer de mama em mulheres para clorpirifós, tebufós e forato ${ }^{73}$. Porém, para câncer de bexiga ${ }^{27,28}$, câncer de pâncreas ${ }^{74} \mathrm{e}$ melanoma ${ }^{74}$ não houve associação positiva significativa com exposição aos agrotóxicos (Quadro 4).

Em um estudo ${ }^{52}$, a ocorrência de instabilidade genômica foi associada positivamente à exposição aos agrotóxicos (Quadro 3).

Dentre as alterações bioquímicas (Quadro 3), dois estudos ${ }^{39,40}$ demonstraram maiores concentrações séricas de metais (zinco, chumbo, cobre, arsênio, manganês e níquel) em agricultores expostos do que nos controles, mesmo em períodos de baixa aplicação ${ }^{39}$. Também foram observadas alterações na glicemia, na função hepática e no lipidograma ${ }^{37,55}$.

Em relação às doenças mentais (Quadro 4) houve associações positivas para depressão e ansiedade autorreferida em expostos a organofosforados ${ }^{23}$. Campos et al. ${ }^{22}$ verificaram que a exposição a determinados IA associou-se positivamente à depressão autorreferida; Kim et al. ${ }^{24}$ observaram associações positivas entre casos moderados/severos de intoxicação aguda por agrotóxicos e tentativa de suicídio.

Para as doenças neurológicas (Quadro 4) identificaram-se associações positivas entre a ocupação (agricultor) e alterações cognitivas ${ }^{18}$. Resultados similares ocorreram em outras duas pesquisas ${ }^{19,20}$. Dois estudos revelaram associações positivas entre exposição a agrotóxicos e Doença de Parkinson/Parkinsonismo ${ }^{16,17}$. Um estudo ${ }^{21}$ identificou que a exposição aos agrotóxicos ao longo da vida está associada positivamente a alterações no equilíbrio postural. Bayrami et al. ${ }^{54}$, entretanto, não observaram associação entre ocupação e desordens neuropsicológicas, apesar de identificarem níveis da enzima colinesterase eritrocitária ou acetilcolinesterase (AChE) significativamente menores nos agricultores do que nos controles. Especialistas têm demonstrado que alterações da atividade da AChE e da colinesterase plasmática ou butirilcolinesterase (BChE) estão envolvidas na patogênese de doenças neurológicas e provavelmente em alterações mentais ${ }^{76}$.

Estudos identificaram associações positivas entre exposição a agrotóxicos e atividade reduzida de $\mathrm{AChE}^{38,41,46,59}$ e de $\mathrm{BChE}^{37,38,44,54}$. Hongsibsong et al. ${ }^{41}$ revelaram associações positivas entre redução nos níveis de AChE e sintomas de saúde. De Oliveira e Ehrhardt ${ }^{43}$ não verificaram diferenças significativas nos níveis de AChE e BChE entre os períodos de baixa e alta aplicação de agrotóxicos (Quadro 3). 
Alterações da tireoide foram avaliadas em dois estudos $^{29,30}$ (Quadro 4). No primeiro, as associações foram fracas e inconsistentes e, no segundo, a exposição a ditiocarbamatos associou-se positivamente a alterações na função da tireoide em homens. Ainda no grupo de distúrbios hormonais/metabólicos, destaca-se o estudo de LaVerda ${ }^{31}$, que demonstrou associações positivas entre ganhos de IMC e exposição a atrazina e triazina em aplicadores de agrotóxicos.

Com relação aos demais desfechos crônicos (Quadro 4), a exposição à ditiocarmabatos e ao glifosato foram associadas positivamente à artrite reumatoide em mulheres ${ }^{36}$. Encontraram-se associações positivas entre exposição aos agrotóxicos (clorimurom etil, paraquate e butilato) e doença renal em estágio avançado ${ }^{32}$; doenças respiratórias ${ }^{33}$, para os ingredientes ativos 2,4D, atrazina, glifosato, carbaril, malationa, permetrina e warfarina; e alterações auditivas para exposição a agrotóxicos em geral ${ }^{34,35}$.

Sinais e sintomas clínicos de intoxicação aguda foram associados positivamente ao uso de agrotóxicos para as variáveis: tempo/duração da exposição $0^{61,64,65,67}$ e toxicidade do agrotóxico ${ }^{60,61,63,66}$. Para a variável quantidade de pesticidas, os achados foram controversos $^{60,66}$. Em alguns estudos, o uso de medidas de proteção teve associação inversa com a ocorrência de intoxicação aguda ${ }^{60,64-66} \mathrm{e}$, em dois estudos, a escolaridade também associou-se negativamente com a chance de intoxicação aguda ${ }^{60,64}$. Ser mulher foi um fator de proteção para intoxicação aguda e práticas inadequadas de manuseio de pulverizadores associaram-se positivamente a sinais/sintomas de intoxicação aguda $^{63}$. Destaca-se o estudo de Siqueira ${ }^{70}$ que identificou pior qualidade de vida em aplicadores de agrotóxico em comparação aos não aplicadores.

\section{Discussão}

Esta revisão evidenciou a diversidade de métodos utilizados para avaliação da exposição de agricultores a agrotóxicos e dos desfechos nos estudos selecionados. Apesar disso, os estudos revelaram associações positivas significativas entre exposição aos agrotóxicos e condições subclínicas, agravos crônicos e sinais/sintomas de intoxicação aguda. A seguir, são pontuados alguns aspectos relacionados às limitações dos estudos analisados.

\section{Limitações quanto à avaliação da exposição aos agrotóxicos}

A maioria dos estudos avaliou a exposição aos agrotóxicos por meio de questionários, com o objetivo de detalhar as características dos processos de trabalho na agricultura - atividade em que a exposição se dá de forma mais acentuada. O uso de questionários tem como vantagens a fácil execução, a agilidade e o baixo custo ${ }^{78}$. Porém, por abordar questões relacionadas ao uso de um produto tóxico para a saúde humana e ambiental, podem ocorrer alguns constrangimentos por parte dos participantes dos estudos ao responder perguntas sobre a idade de início de contato, as doses administradas e o nome comercial dos agrotóxicos utilizados, por exemplo - o que pode ocasionar omissão de respostas ou falsas informações, resultando em exposição subestimada, ou em ausência ou fraca associação entre a exposição aos IA e agravos à saúde, como observado no estudo de Boulanger ${ }^{28}$ para câncer de bexiga. Tais vieses de informação podem acentuar-se em casos de baixa escolaridade devido ao desconhecimento do entrevistado, conforme notou-se no estudo de Salameh e Saleh ${ }^{67}$. A prática de utilizar IAs não recomendados para determinada cultura e o emprego de mais de um tipo de IA em uma única cultura também podem induzir a vieses de informação nessa população. No Brasil, relatórios do Programa Nacional de Análise de Resíduos de Agrotóxicos ${ }^{79}$ têm demonstrado ao longo dos anos que essas práticas são frequentes entre os agricultores.

Com relação ao uso de biomarcadores de exposição, apenas seis estudos dosaram metabólitos de IA em fluidos corporais. Tal achado, provavelmente, justifica-se pela necessidade de estrutura laboratorial complexa, com equipamentos sofisticados e recursos humanos qualificados elevando o custo das pesquisas. Somam-se a isso as grandes distâncias percorridas entre as áreas agrícolas e as dificuldades de transporte das amostras para os laboratórios ${ }^{5}$. Além disso, recomenda-se que o momento da coleta das amostras biológicas seja o período de maior exposição aos agrotóxicos, que geralmente ocorre nas etapas de preparo da terra, acompanhamento e crescimento da lavoura, conforme observado no estudo de Lerro $^{53}$ e Piccoli ${ }^{29}$. A definição do momento da coleta das amostras dos fluidos também deve considerar a meia-vida do agrotóxico (tempo requerido para que a metade da concentração do agrotóxico seja eliminada pelo organismo), pois, caso contrário, pode levar a resultados negativos ${ }^{5}$.

Destaca-se que a meia-vida dos organofosforados e dos carbamatos é curta. De uma maneira geral, esses compostos químicos são agrotóxicos não persistentes, ou seja, uma vez presentes em ambientes naturais decompõem-se em dias ou semanas ${ }^{80}$. No entanto, por mais que sejam degradados rapidamente, podem gerar subprodutos ou metabólitos mais tóxicos decorrentes de sua degradação ${ }^{81}$.

Segundo Oliveira-Silva et al. ${ }^{82}$, os organofosforados e carbamatos são denominados agentes anticolinesterásicos por possuírem o mesmo mecanismo tóxico de ação: inibem a ação das colinesterases, 
enzimas presentes nos sistemas nervosos central, periférico, placa motora e no tecido sanguíneo (AChE e BChE), resultando em diversos efeitos neurotóxicos.

Na prática clínica, para fins de diagnóstico de intoxicação por organofosforados ou carbamatos, deve-se conhecer o tempo de meia-vida dessas enzimas $^{5}$ : para a AChE é de três meses e para a BChE é de uma semana. Tais diferenças indicam que a AChE reflete melhor um efeito tóxico crônico, por ser afetada por mais tempo, enquanto a BChE, por apresentar inibição menos prolongada, funciona como um biomarcador importante para exposição recente. Porém, segundo Klassen ${ }^{83}$, ao se utilizar esses marcadores na prática clínica, para fins de diagnóstico de intoxicação por organofosforados, é preciso levar em consideração as diferenças entre os compostos químicos, já que inibem as colinesterases de maneiras distintas (por exemplo: malation, diazinon, clorfirifós e diclovós são fortes inibidores da BChE e não da AChE). Enquanto isso, em quadros de intoxicação por carbamatos, as colinesterases retornam aos seus níveis normais mais rapidamente, pois a inibição enzimática é transitória e rapidamente reversível, tendo, portanto, um valor diagnóstico limitado. Nesse sentido, quando há suspeita de intoxicação por carbamato, a dosagem de AChE desse ser feita o mais rápido possível (em poucas horas) pois é muito frequente a não detecção de níveis reduzidos dessa enzima, mesmo na presença de sintomas de intoxicação severa por esse ingrediente ativo. A inibição da BChE por carbamatos também ocorre, porém o grau de inibição varia conforme o composto.

Os organofosforados e os carbamatos são os maiores responsáveis pelas intoxicações humanas no mundo ${ }^{84}$. Por essa razão, alguns países da Europa, os EUA, a China e, mais recentemente, o Brasil ${ }^{85}$ baniram alguns IA que pertencem ao grupo dos organofosforados, como: os metamidofóes, tricloform e forato. No entanto, a legislação brasileira ainda permite o uso de outros, como: o acefato, que já foi banido em 28 países da União Européia, China, Palestina e Omã ${ }^{86}$, por causar efeitos neurotóxicos e, possivelmente, câncer, além de induzir toxicidade reprodutiva $^{87}$. A diazinona também banida em Moçambique, Palestina e em 28 países da Europa ${ }^{86}$, foi classificada pela Agência Internacional de Pesquisa em Câncer como provável cancerígeno em humanos ${ }^{75}$.

Todas essas questões relacionadas à avaliação de biomarcadores de exposição são complexas e podem influenciar o tamanho amostral limitando o número de participantes recrutados para os estudos, conforme observado em algumas pesquisas ${ }^{41,53,56}$.

No que tange à identificação do IA ou de seu GQ, onze estudos $22,26,29,32,33,36,53,71-74$, verificaram uma associação positiva significativa entre os IA utilizados e desfechos à saúde: transtornos mentais e depressão ${ }^{22}$, artrite reumatoide ${ }^{36}$, alterações nos níveis de hormônios tireoidianos ${ }^{29}$, doença renal em estágio terminal $^{32}$, estresse oxidativo ${ }^{53}$, presença de distúrbios respiratórios ${ }^{33}$ e câncer ${ }^{26,71-74}$. Já o estudo de Boada et al. ${ }^{27}$ não identificou associação significativa positiva entre IA e câncer de bexiga. Além disso, em alguns estudos, coletou-se informações sobre o GQ e os IA - porém, não foi possível utilizar estas variáveis em modelos estatísticos ${ }^{19,38-41,52,60-62,64,66,69}$, provavelmente devido à baixa frequência da distribuição dos IA/GQ de agrotóxicos na amostra, limitando o seu uso como uma variável de exposição principal e levando-a a ser substituída por outras variáveis de menor especificidade, como uso de agrotóxicos em geral, índices de exposição, classificação dos agrotóxicos por toxicidade ou finalidade de uso, entre outras.

É importante considerar também que os estudos científicos avaliados são limitados quanto à análise de possíveis efeitos tóxicos decorrentes de exposições mistas de agrotóxicos (com dois ou mais IA) em humanos. Ou seja, a maioria não foi capaz de avaliar os efeitos sinérgicos que podem ocorrer quando mais de um IA e outros compostos químicos se fazem presentes nos produtos formulados. Adicionalmente, no cotidiano das populações agrícolas, ocorre a exposição simultânea a múltiplas misturas por diferentes vias de penetração (inalatória ou dérmica durante os processos de trabalho, ou pela via oral, através do consumo de alimentos e água contaminados) ${ }^{87}$, mais um fator complicador para a avaliação da exposição aos agrotóxicos.

\section{Limitações quanto à avaliação dos desfechos relacionados à saúde}

Dos estudos selecionados, 21 utilizaram biomarcadores de efeito ou indicadores bioquímicos como uma variável-resposta à exposição aos agrotóxicos 37-46,48-53,55-59. Os biomarcadores de efeito identificam os estágios de progressão de um quadro subclínico antes que a manifestação dos sinais e sintomas estejam presentes e a doença diagnosticada, funcionando como preditores do desenvolvimento de agravos crônicos ${ }^{5}$. Entretanto, o elevado custo envolvido na coleta, armazenamento, processamento e análise dos fluidos biológicos pode limitar a obtenção de uma amostra representativa e, dessa forma, restringir a generalização dos resultados a populações semelhantes. O uso de amostragem por conveniência em tais estudos torna-se um ato frequente, o que é compreensível, porém perde-se em validade externa.

Além disso, devem-se considerar outras limitações desses biomarcadores de efeito, especialmente quanto ao uso das colinesterases para o 
monitoramento biológico ocupacional ou na prática clínica, a saber: a) grande variabilidade individual dos níveis basais dessas enzimas, não sendo adequado estabelecer um valor universal de referência para indicar intoxicação; b) dificuldade em se estabelecer valores pré-exposição para populações agrícolas, que em geral crescem e vivem nos locais de trabalho, sendo, portanto, regularmente expostas, o que impossibilita a definição de valores basais pré-exposição (uma opção seria considerar a medida na fase de baixa exposição, mas para determinadas culturas agrícolas o uso de agrotóxicos é quase ininterrupto ${ }^{88}$; c) a presença de outros problemas de saúde que alteram os níveis dessas enzimas no sangue - a BChE tem suas concentrações alteradas em quadros de anemias hemolíticas, anemia perniciosa, recuperação de hemorragia e condições associadas a reticulose. A AChE pode ter seus níveis reduzidos por outros fatores como ingestão de álcool, desnutrição, gravidez precoce, uso de cocaína, contraceptivos, determinados medicamentos, síndrome nefrótica e doenças hepáticas; d) diferenças nos valores de AChE e BChE em função da sensibilidade e especificidade dos diferentes métodos laboratoriais empregados $^{89}$; e) ausência de consenso sobre o ponto de corte de medição da atividade dessas enzimas para a definição de intoxicação ${ }^{82}$. A exemplo, a norma regulamentadora do trabalho Programa de Controle Médico de Saúde Ocupacional (NR-7) utiliza como indicador de intoxicação por agrotóxico depressão da atividade inicial da BChE de $30 \%$ em comparação aos níveis pré-exposição, de 50\% para AChE e de $25 \%$ para o sangue total. Alguns toxicologistas recomendam outros valores de referência segundo o grau de intoxicação - leve, moderado e severo ${ }^{90,91}$.

Mesmo diante de todas essas limitações, tais enzimas continuam sendo os indicadores de preferência para a avaliação de intoxicação por inseticidas organofosforados e/ou carbamatos nos serviços de saúde ${ }^{89}$.

No entanto, vale destacar a possibilidade de se avaliar outros marcadores biológicos, tais como biomarcadores de genotoxidade e de estresse oxidativo, que podem complementar os resultados encontrados pelas colinesterases e servir de indicativos dos danos associados à exposição crônica aos agrotóxicos, conforme observado em alguns estudos desta revisão $40,44-48,54,55,58$.

Os ensaios de genotoxicidade para avaliação de danos do DNA através do teste Cometa e teste do micronúcleo fundamentam-se em alterações nível celular que ocorrem no gene/DNA da célula. O teste Cometa detecta lesões reparáveis recentes, tais como quebras e locais com álcoois alcalinos, enquanto o teste do micronúcleo (MN) detecta dano não reparável, permanente. Entretano, alguns fatores como o ambiente de trabalho, uso de equipamento de proteção individual, tempo de exposição e condições da exposição podem afetar os níveis de danos citogenéticos e genotóxicos ${ }^{83}$.

A Agência Internacional de Pesquisa em Câncer ${ }^{92}$ descreveu três mecanismos predominantes para a genotoxicidade de metais que estão presentes no processo de carcinogênese: (1) interferência com a regulação redox celular e indução de estresse oxidativo, o que pode causar danos oxidativo ao DNA ou desencadear cascatas de sinalização levando a estimulação do crescimento celular; (2) inibição dos principais sistemas de reparo do DNA, resultando em instabilidade genômica e acumulação de mutações críticas; (3) desregulação da proliferação celular por indução de caminhos de sinalização ou inativação de controles de crescimento tais como genes supressores de tumor. Portanto, tais biomarcadores de efeito à exposição aos agrotóxicos podem sugerir condições internas alteradas de maior risco para o desenvolvimento de câncer.

Íons metálicos contidos em alguns agrotóxicos podem interferir com etapas distintas de vários sistemas de reparo do DNA e produzir espécies reativas de oxigênio (ROS), levando ao dano oxidativo do DNA. A exposição a diferentes categorias de pesticidas (por exemplo: organofosforados, carbamatos ou piretróides) pode levar ao estresse oxidativo em indivíduos que pulverizam esses agrotóxicos. Os mecanismos propostos na literatura são: formação de espécies reativas de oxigênio, geração de radicais livres, alteração da atividade de enzimas antioxidantes, como o aumento nos níveis da superóxido dismutase (SOD) e peroxidação lipídica ${ }^{9}$.

Assim, a avaliação de saúde desses trabalhadores que estão expostos aos agrotóxicos deveria apoiar-se neste tripé: histórico detalhado da exposição, avaliação clínica do estado de saúde e diagnóstico laboratorial por meio do uso de diferentes biomarcadores de efeito.

No que tange às categorias de agravos crônicos à saúde identificados, observou-se que, em 24 estudos, os autores recorreram a definições e critérios diagnósticos validados pela comunidade científica $^{17,18,20,26-28,30-34,38,43,45,54,60,61,69,71,72}$. Entretanto, o emprego de perguntas amplas tal como "qual o seu problema de saúde?", como descrito no artigo de Jacobson et al. ${ }^{69}$, não permite conhecer com precisão qual é o agravo/doença que poderia estar associado à exposição aos agrotóxicos na população estudada, limitando a interpretação dos achados encontrados. Destaca-se o estudo de Siqueira et al. ${ }^{70}$, que revelou que aqueles que não aplicavam agrotóxicos foram 
os que mais relataram queixas sobre saúde. Porém, ao avaliar a qualidade de vida, através de um instrumento validado, os que aplicavam agrotóxicos referiram uma pior qualidade de vida. Daí, a importância cada vez maior de se medir também o conceito ampliado de saúde. Segundo Szwarcwald et al. ${ }^{93}$, a autoavaliação de saúde é um indicador que expressa a percepção do indivíduo sobre o seu estado de saúde sendo reconhecido internacionalmente por apresentar boa associação com indicadores de morbi-mortalidade de doenças crônicas. Moreira et al. ${ }^{94}$, ao avaliar uma amostra representativa de trabalhadores brasileiros, mostraram que a autoavaliação de saúde ruim/muito ruim associou-se positiva e significativamente ao trabalho em atividades agrícolas, se comparado àqueles que não desenvolviam tais atividades.

\section{Limitações quanto à amostragem}

O fato de se planejar um tamanho amostral adequado para representar a população que se pretende estudar nem sempre é acompanhado da seleção probabilística dos indivíduos que comporão a amostra, como ocorreu na maioria dos estudos que utilizaram biomarcadores de efeitos e nas pesquisas de Rosales $^{44}$ e Faria et al. ${ }^{64}$. Tal fato prejudica a extrapolação dos resultados para outras populações de agricultores, perdendo-se em validade externa.

\section{Limitações quanto ao delineamento dos estudos}

Estudos transversais fornecem informações sobre o diagnóstico de saúde de um grupo populacional e, por isso, auxiliam o planejamento local em saúde. Entretanto, não testam hipóteses de causalidade entre exposição e desfecho, já que não conseguem identificar se a exposição antecedeu ou não o desfecho, uma vez que os dados sobre ambos são coletados simutalneamente. Vieses de causalidade reversa são frequentes nesse tipo de estudo. Os resultados encontrados por Dasgupta et al. ${ }^{60}$ (associação inversa entre quantidade de agrotóxico utilizado e chance de intoxicação) corroboram essa afirmação. Já estudos caso-controle possibilitam o cálculo de medidas de efeito, e, portanto, testam a causalidade entre a exposição e o desfecho. Entretanto, os vieses de seleção ocorrem regularmente, devido à dificuldade de identificação de controles representativos da mesma base populacional dos casos. Assim, a ausência de associação entre exposição a organoclorados e câncer de bexiga observada no estudo de Boada et al. ${ }^{27}$ pode ser atribuída ao uso de controles de base hospitalar. No tocante aos estudos de coorte, a principal limitação decorre do tempo de seguimento da população, especialmente para doenças crônicas, como o câncer, que demandam tempo de seguimento suficientemente longo para se observar a incidência do mesmo, favorecendo as perdas ao longo do seguimento e, dessa forma, enviesando os resultados. Provavelmente a ausência de associação entre exposição aos agrotóxicos e câncer de bexiga no estudo de Boulanger et al. ${ }^{28}$ atribuem-se ao curto tempo de seguimento (cinco anos).

\section{Conclusão}

As evidências identificadas nesta revisão sugerem a necessidade de se complementar a avaliação de saúde do trabalhador exposto aos agrotóxicos com monitoramento biológico utilizando biomarcadores de efeito de genotoxicidade e citotoxicidade, a fim de se promover e ampliar a vigilância da exposição e de intoxicações crônicas, tais como o câncer.

Para estudos futuros, aconselha-se incluir outras formas de se avaliar a saúde de populações expostas aos agrotóxicos, incorporando também o conceito ampliado de saúde, por meio do indicador "autoavaliação de saúde”, pois esse indicador tem sido reportado como um bom marcador para avaliação de risco de morbi-mortalidade - tema ainda muito pouco explorado nos estudos que avaliam a saúde das populações agrícolas.

Esta revisão não esgota as evidências científicas referentes ao tema, porém fornece indícios de que a avaliação da exposição aos agrotóxicos é complexa e a diversidade de danos associados à saúde é alarmante, revelando que esse grupo de trabalhadores apresenta risco elevado para a ocorrência de agravos crônicos (câncer, doenças mentais, neurológicas, endócrinas, renais, auditivas, respiratórias e autoimune), efeitos subclínicos (danos genéticos e alterações bioquímicas) e sinais e sintomas clínicos de intoxicação aguda. Recomenda-se que órgãos competentes considerem todos estes achados para fins de registro e reavaliação de agrotóxicos no Brasil, uma vez que o país é o maior consumidor de agrotóxicos do mundo ${ }^{95}$. Na incerteza dos danos, os princípios da precaução e da prevenção devem ser priorizados com o intuito de proteger a saúde da população.

\section{Contribuições de autoria}

Nogueira, FAM, Szwarcwald, CL e Damacena, GN contribuíram igualmente para a concepção do trabalho, levantamento e análise das informações e elaboração, revisão e aprovação da versão final publicada. As autoras assumem integral responsabilidade pelo trabalho e o conteúdo aqui publicado. 


\section{Referências}

1. Oliveira Junior PHB. Notas sobre a história da agricultura através do tempo. Rio de Janeiro: FASE - Federação de Órgão para Assistência Social e Educacional; 1989.

2. Weisheimer N. Desenvolvimento rural, capitalismo e agricultura familiar. Olhares sociais. 2013;2(1):51-78.

3. Miranda AC, Moreira JC, Peres F. Neoliberalismo, uso de agrotóxicos e a crise da soberania alimentar no Brasil. Cien Saude Colet [Internet]. 2007 [citado em 20 maio 2018];12(1):7-14. Disponível: http://www.scielo.br/scielo.php?pid=S1413$81232007000100002 \&$ script $=$ sci_abstract\&tlng $=p t$

4. Food and Agriculture Organization of the United Nations, World Health Organization.Guidelines on highly hazardous pesticides. Roma: Food and Agriculture Organization of the United Nations; 2016.

5. Peres F, Moreira JC. É veneno ou é remédio? agrotóxicos, saúde e ambiente. Rio de Janeiro: Fiocruz; 2003.

6. Vandenbergh JG. Animal models and studies of in utero endocrine disruptor effects. ILAR J [Internet]. 2004 [cited 2018 May 10];45(4):43842. Available from: http://www.ncbi.nlm.nih.gov/ pubmed/15454682

7. Sebastian R, Raghavan SC. Induction of DNA damage and erroneous repair can explain genomic instability caused by endosulfan. Carcinogenesis [Internet]. 2016 [cited 2018 May 10];37(10):929-40. Available from: https://academic.oup.com/carcin/ article-lookup/doi/10.1093/carcin/bgw081

8. International Agency for Research on Cancer. IARC Monographs evaluate DDT, lindane, and 2,4-D [Internet]. Lyon; 2015 [cited 2018 Apr 15]. Available from: http://www.iarc.fr/en/media-centre/ pr/2015/pdfs/pr236_E.pdf

9. Abdollahi M, Ranjbar A, Shadnia S, Nikfar S, Rezaie A. Pesticides and oxidative stress: a review. Med Sci Monit [Internet]. 2004 [cited 2018 May 28];10(6):141-7. Available from: https://www.ncbi. nlm.nih.gov/pubmed/15173684

10. Rehman H, Aziz AT, Saggu S, VanWert AL, Zidan N, Saggu S. Additive toxic effect of deltamethrin and cadmium on hepatic, hematological, and immunological parameters in mice. Toxicol Ind Health [Internet]. 2017 [cited 2018 May 10];33(6):495-502. Available from: http://www. ncbi.nlm.nih.gov/pubmed/28071525

11. Greenpeace. Agricultura tóxica: um olhar sobre o modelo agrícola brasileiro. São Paulo: Greenpeace Brasil; 2017.

12. Rendón-von Osten J, Dzul-Caamal R. Glyphosate residues in groundwater, drinking water and urine of subsistence farmers from intensive agriculture localities: a survey in Hopelchén, Campeche, Mexico. Int J Environ Res Public Health [Internet].
2017 [cited 2018 May 10];14(6):595. Available from: http://www.mdpi.com/1660-4601/14/6/595

13. Palma DCA, Lourencetti C, Uecker ME, Mello PRB, Pignati WA, Dores EFGC. Simultaneous determination of different classes of pesticides in breast milk by solid-phase dispersion and GC/ ECD. J Braz Chem Soc [Internet]. 2014 [cited 2018 May 10];25(8):1419-30. Available from: http:// www.scielo.br/scielo.php?script =sci_arttext\&pid $=$ S0103-50532014000800013

14. Breilh J. Epidemiologia crítica: ciência emancipadora e interculturalidade. Rio de Janeiro: Fiocruz; 2006.

15. De Souza Porto MF. Riscos, incertezas e vulnerabilidades: transgênicos e os desafios para a ciência e a governança. Polít Soc. 2005;4(7):77-103.

16. Moisan F, Spinosi J, Delabre L, Gourlet V, Mazurie JL, Bénatru I, et al. Association of parkinson's disease and its subtypes with agricultural pesticide exposures in men: A case-control study in France. Environ Health Perspect [Internet]. 2015 [cited 2018 Apr 15];123(11):1123-9. Available from: https:/ehp.niehs.nih.gov/doi/pdf/10.1289/ ehp.1307970

17. Nielsen SS, Hu S-C, Checkoway H, Negrete M, Palmández P, Bordianu T, et al. Parkinsonism signs and symptons in agricultural pesticide handlers in Washington State. J Agromedicine [Internet]. 2017 [cited 2018 Apr 14];22(3):215-21. Available from: https://www.ncbi.nlm.nih.gov/pmc/articles/ PMC5533575/pdf/nihms880727.pdf

18. Nguyen HT, Quandt SA, Summers P, Morgan TM, Chen H, Walker FO, et al. Learning ability as a function of practice: Does it apply to farmworkers? J Occup Env Med [Internet]. 2015 [cited 2018 May 29];57(6):678-81. Available from: https://www.ncbi. nlm.nih.gov/pmc/articles/PMC4461507/

19. Zhang X, Wu M, Yao H, Yang Y, Cui M, Tu Z, et al. Pesticide poisoning and neurobehavioral function among farm workers in Jiangsu, People's Republic of China. Cortex. 2016;74:396-404.

20. Jamal F, Haque QS, Singh S. Interrelation of Glycemic Status and Neuropsychiatric Disturbances in Farmers with Organophosphorus Pesticide Toxicity. Open Biochem J [Internet]. 2016 [cited 2018 May 10];10(1):27-34. Available from: https://benthamopen.com/FULLTEXT/ TOBIOCJ-10-27

21. Sunwook K, Nussbaum MA, Quandt SA, Laurienti PJ, Arcury TA. Effects of lifetime occupational pesticide exposure on postural control among farmworkers and non-farmworkers. J Occup Environ Med [Internet]. 2016 [cited 2018 Apr 15];58(2):133-9. Available from: https://www.ncbi. nlm.nih.gov/pmc/articles/PMC4746006/

22. Campos E, da Silva VSP, De Melo MSC, Otero UB. Exposure to pesticides and mental disorders 
in a rural population of Southern Brazil.

Neurotoxicology. 2017;56:7-16.

23. Harrison V, Mackenzie Ross S. Anxiety and depression following cumulative low-level exposure to organophosphate pesticides. Environ Res. 2016;151:528-36.

24. Kim J, Shin DH, Lee WJ. Suicidal ideation and occupational pesticide exposure among male farmers. Environ Res. 2014;128:52-6.

25. Lemarchand C, Tual S, Boulanger M, LevêqueMorlais N, Perrier S, Clin B, et al. Prostate cancer risk among french farmers in the AGRICAN cohort. Scand J Work Environ Heal [Internet]. 2016 [cited 2018 June 13];42(2):144-52. Available from: http://www.sjweh.fi/show_abstract.php?abstract_ id $=3552 \&$ fullText $=1$ \#box-fullText

26. Bonner MR, Lee WJ, Sandler DP, Hoppin JA, Dosemeci M, Alavanja MC. Occupational exposure to carbofuran and the incidence of cancer in the Agricultural Health Study. Environ Health Perspect [Internet]. 2005 [cited 2018 May 13];113(3):2859. Available from: https://ehp.niehs.nih.gov/ doi/full/10.1289/ehp.7451?url_ver=Z39.882003\&rfr_id $=$ ori:rid:crossref.org\&rfr_dat $=\mathrm{cr}_{-}$ pub\%3dp̄ubmed

27. Boada LD, Henríquez-Hernández LA, Zumbado M, Almeida-González M, Álvarez-León EE, Navarro P, et al. Organochlorine Pesticides Exposure and Bladder Cancer: Evaluation from a GeneEnvironment Perspective in a Hospital-Based CaseControl Study in the Canary Islands (Spain). J Agromedicine. 2016;21(1):34-42.

28. Boulanger M, Tual S, Lemarchand C, Guizard AV, Velten M, Marcotullio E, et al. Agricultural exposure and risk of bladder cancer in the AGRIculture and CANcer cohort. Int Arch Occup Environ Health [Internet]. 2017 [cited 2018 May 15];90(2):169-78. Available from: http://link. springer.com/10.1007/s00420-016-1182-y

29. Piccoli C, Cremonese C, Koifman RJ, Koifman S, Freire C. Pesticide exposure and thyroid function in an agricultural population in Brazil. Environ Res. 2016;151:389-98.

30. Medda E, Santini F, De Angelis S, Franzellin F, Fiumalbi C, Perico A, et al. Iodine nutritional status and thyroid effects of exposure to ethylenebisdithiocarbamates. Environ Res. 2017;154:152-9.

31. LaVerda NL, Goldsmith DF, Alavanja MCR, Hunting KL. Pesticide exposures and body mass index (BMI) of pesticide applicators from the agricultural health study. J Toxicol Environ Heal Part A. 2015;78(20):1255-76.

32. Lebov JF, Engel LS, Richardson D, Hogan SL, Sandler DP, Hoppin JA, et al. Pesticide exposure and end-stage renal disease risk among wives of pesticide applicators in the Agricultural Health Study. Environ Res [Internet]. 2015 [cited 2018 May 29];143(0 0):198-210. Available from: https:// www.ncbi.nlm.nih.gov/pmc/articles/PMC4662544/
33. Hoppin JA, Umbach DM, Long S, London SJ, Henneberger PK, Blair A, et al. Pesticides are associated with allergic and non-allergic wheeze among male farmers. Environ Health Perspect [Internet]. 2017 [cited 2018 May 29];125(4):53543. Available from: https://ehp.niehs.nih.gov/ doi/full/10.1289/EHP315?url_ver=Z39.882003\&rfr_id = ori:rid:crossref.org\&rfr_dat $=\mathrm{cr}$ pub\%3dp̄ubmed

34. Bazilio MMDM, Frota S, Chrisman JR, Meyer A, Asmus CIRF, Camara VM. Processamento auditivo temporal de trabalhadores rurais expostos a agrotóxico. J Soc Bras Fonoaudiol [Internet]. 2012 set [citado em 29 maio 2018];24(2):174-80. Disponível: http://www.scielo.br/pdf/jsbf/v24n2/ pt_15.pdf

35. Sena TRR de, Vargas MM, Oliveira CC da C. Saúde auditiva e qualidade de vida em trabalhadores expostos a agrotóxicos. Cien Saude Colet [Internet]. 2013 [citado em 27 abr 2018];18(6):1753-61. Disponível: http://www.scielo. br/scielo.php?script =sci_arttext\&pid $=$ S141381232013000600026\&lng $=$ pt\&tlng $=p t$

36. Parks CG, Hoppin JA, De Roos AJ, Costenbader KH, Alavanja MC, Sandler DP. Rheumatoid arthritis in agricultural health study spouses: associations with pesticides and other farm exposures. Environ Health Perspect [Internet]. 2016 [cited 2018 May 14];124(11):1728-34. Available from: https://ehp. niehs.nih.gov/doi/pdf/10.1289/EHP129

37. García-García CR, Parrón T, Requena M, Alarcón R, Tsatsakis AM, Hernández AF. Occupational pesticide exposure and adverse health effects at the clinical, hematological and biochemical level. Life Sci. 2016;145:274-83.

38. Aroonvilairat S, Kespichayawattana W, Sornprachum T, Chaisuriya P, Siwadune T, Ratanabanangkoon K. Effect of pesticide exposure on immunological, hematological and biochemical parameters in thai orchid farmers - a crosssectional study. Int J Environ Res Public Health [Internet]. 2015 [cited 2018 Apr 14];12(6):5846-61. Available from: https://www.ncbi.nlm.nih.gov/pmc/ articles/PMC4483675/

39. Rocha GHO, Lini RS, Barbosa F, Batista BL, de Oliveira Souza VC, Nerilo SB, et al. Exposure to heavy metals due to pesticide use by vineyard farmers. Int Arch Occup Environ Health [Internet]. 2015 [cited 2018 May 10];88(7):875-80. Available from: http://dx.doi.org/10.1007/s00420-014-1010-1

40. Alves JS, Da Silva FR, Da Silva GF, Salvador M, Kvitko K, Rohr P, et al. Investigation of potential biomarkers for the early diagnosis of cellular stability after the exposure of agricultural workers to pesticides. An Acad Bras Cienc [Internet]. 2016 [cited 2018 June 13];88(1):349-60. Available from: http:/www.scielo.br/pdf/aabc/v88n1/0001-3765aabc-201520150181.pdf

41. Hongsibsong S, Sittitoon N, Sapbamrer R. Association of health symptoms with low-level 
exposure to organophosphates, DNA damage, AChE activity, and occupational knowledge and practice among rice, corn, and double-crop farmers. J Occup Health [Internet]. 2017 [cited 2018 Apr 10];59(2):165-76. Available from: https:// www.ncbi.nlm.nih.gov/pmc/articles/PMC5478518/

42. Lebailly P, Mirey G, Herin F, Lecluse Y, Salles B, Boutet-Robinet E. DNA damage in B and T lymphocytes of farmers during one pesticide spraying season. Int Arch Occup Environ Health [Internet]. 2015 [cited 2018 May 10];88(7):963-72. Available from: https://www.ncbi.nlm.nih.gov/pmc/ articles/PMC4564440/

43. De Oliveira GH, Enrhardt A. Determinação da atividade da colinesterase plasmática e eritrocitária após exposição aguda a organofosforaados e carbamatos em agricultores do municíio de Chapada, RS. Rev Bras Análises Clin. 2015;47:159-64.

44. Rosales J. Uso de marcadores genotoxicológicos para la evaluación de agricultores expuestos a plaguicidas organofosforados. An Fac Med [Internet]. 2015 [citado em 10 abr 2018];76(3):247-52. Disponível: http:// dx.doi.org/10.15381/anales.v76i3.11233

45. Carbajal-López Y, Gómez-Arroyo S, VillalobosPietrini R, Calderón-Segura ME, MartínezArroyo A. Biomonitoring of agricultural workers exposed to pesticide mixtures in Guerrero state, Mexico, with comet assay and micronucleus test. Environ Sci Pollut Res [Internet]. 2016 [cited 2018 Apr 13];23(3):2513-20. Available from: https://link.springer.com/content/ pdf/10.1007\%2Fs11356-015-5474-7.pdf

46. Simoniello MF, Kleinsorge EC, Carballo MA. Evaluacion bioquimica de trabajadores rurales expuestos a pesticidas. Medicina. 2010;70:489-98.

47. Tumer TB, Savranoglu S, Atmaca P, Terzioglu G, Sen A, Arslan S. Modulatory role of GSTM1 null genotype on the frequency of micronuclei in pesticide-exposed agricultural workers. Toxicol Ind Health. 2016;32(12):1942-51.

48. Saad-Hussein A, Noshy M, Taha M, El-Shorbagy H, Shahy E, Abdel-Shafy EA. GSTP1 and XRCC1 polymorphisms and DNA damage in agricultural workers exposed to pesticides. Mutat Res - Genet Toxicol Environ Mutagen. 2017;819:20-5.

49. Mackness B, Durrington P, Povey A, Thomson S, Dippnall M, Mackness M, et al. Paraoxonase and susceptibility to organophosphorus poisoning in farmers dipping sheep. Pharmacogenetics. 2003;13(2):81-8.

50. Rusiecki JA, Freeman LEB, Bonner MR, Alexander M, Chen L, Andreotti G, et al. High pesticide exposure events and dna methylation among pesticide applicators in the agricultural health study. Environ Mol Mutagen [Internet]. 2017 [cited 2018 Apr 27];(58):19-29. Available from: https:// www.ncbi.nlm.nih.gov/pmc/articles/PMC5416937/

51. Gómez-Martín A, Altakroni B, Lozano-Paniagua D, Marginson GP, De Vocht F, Povey AC, et al.
Increased N7-methyldeoxyguanosine DNA adducts after occupational exposure to pesticides and influence of genetic polymorphisms of paraoxonase-1 and glutathione S-transferase M1 and T1. Environ Mol Mutagen. 2015;56(5):437-45.

52. Zeljezic D, Bjelis M, Mladinic M. Evaluation of the mechanism of nucleoplasmic bridge formation due to premature telomere shortening in agricultural workers exposed to mixed pesticides: Indication for further studies. Chemosphere [Internet]. 2015 [cited 2018 Apr 27];120:45-51. Available from: https://www.sciencedirect.com/science/article/pii/ S0045653514007322?via\%3Dihub

53. Lerro CC, Freeman LEB, Portengen L, Kang D, Lee $\mathrm{K}$, Blair A, et al. A longitudinal study of atrazine and 2,4-d exposure and oxidative stress markers among iowa corn farmers. Environ Mol Mutagen [Internet]. 2017 [cited 2018 Apr 27];38(1):30-8. Available from: https://www.ncbi.nlm.nih.gov/pmc/ articles/PMC5763550/

54. Bayrami M, Hashemi T, Malekirad AA, Ashayeri H, Faraji F, Abdollahi M. Electroencephalogram, cognitive state, psychological disorders, clinical symptom, and oxidative stress in horticulture farmers exposed to organophosphate pesticides. Toxicol Ind Health. 2012;28(1):90-6.

55. Madani FZ, Hafida M, Merzouk SA, Loukidi B, Taouli K, Narce M. Hemostatic, inflammatory, and oxidative markers in pesticide user farmers. Biomarkers. 2016;21(2):138-45.

56. Wang L, Liu Z, Zhang J, Wu Y, Sun H. Chlorpyrifos exposure in farmers and urban adults: metabolic characteristic, exposure estimation, and potential effect of oxidative damage. Environ Res. 2016;149:164-70.

57. Costa C, Gangemi S, Giambo F, Rapisarda V, Caccamo D, Fenga C. Oxidative stress biomarkers and paraoxonase 1 polymorphism frequency in farmers occupationally exposed to pesticides. Mol Med Rep [Internet]. 2015 [cited 2018 Apr 14];12(4):6353-7. Available from: https://www. spandidos-publications.com/mmr/12/4/6353

58. Ramirez V, Cuenca P. Micronuclei frequency in lymphocytes of individuals occupationally exposed to pesticides. Rev Biol Trop [Internet]. 2001 [cited 2018 July 4];49(1):1-8. Available from: https://www.scielo.sa.cr/scielo.php?script=sci_artt ext\&pid=S0034-77442001000100001

59. Pakravan N, Shokrzadeh M, Bari MK, Shadboorestan A. Measurement of cholinesterase enzyme activity before and after exposure to organophosphate pesticides in farmers of a suburb region of Mazandaran, a northern province of Iran. Hum Exp Toxicol. 2016;35(3):297-301.

60. Dasgupta S, Meisner C, Wheeler D, Xuyen K, Thi Lam N. Pesticide poisoning of farm workersimplications of blood test results from Vietnam. Int J Hyg Environ Health. 2007;210(2):121-32.

61. Mancini F, Van Bruggen AHC, Jiggins JLS, Ambatipudi AC, Murphy H. Acute pesticide 
poisoning among female and male cotton growers in India. Int J Occup Environ Health. 2005;11(3):221-32.

62. Neupane D, Jørs E, Brandt L. Pesticide use, erythrocyte acetylcholinesterase level and selfreported acute intoxication symptoms among vegetable farmers in Nepal: A cross-sectional study. Environ Heal [Internet]. 2014 [cited 2018 May 12];13(1):1-7. Available from: https://www. ncbi.nlm.nih.gov/pmc/articles/PMC4277821/

63. Oesterlund AH, Thomsen JF, Sekimpi DK, Maziina J, Racheal A, Jørs E. Pesticide knowledge, practice and attitude and how it affects the health of smallscale farmers in Uganda: a cross-sectional study. Afr Health Sci [Internet]. 2014 [cited 2018 May 28];14(2):420-33. Availble from: https://www.ncbi. nlm.nih.gov/pmc/articles/PMC4196420/

64. Faria NMX, Rodrigues Da Rosa JA, Facchini LA. Intoxicações por agrotóxicos entre trabalhadores rurais de fruticultura, Bento Gonçalves, RS. Rev Saude Publica [Internet]. 2009 [citado em $10 \mathrm{abr}$ 2018];43(2):335-44. Disponível em: https://www. scielo.br/pdf/rsp/v43n2/7200.pdf

65. Muñoz-Quezada MT, Lucero B, Iglesias V, Levy K, Muñoz MP, Achú E, et al. Exposure to organophosphate (OP) pesticides and health conditions in agricultural and non-agricultural workers from Maule, Chile. Int J Env Heal Res [Internet]. 2017 [cited 2018 Apr 13];27(1):82-93. Available from: https://www.ncbi.nlm.nih.gov/pmc/ articles/PMC5479415/pdf/nihms856930.pdf

66. Khan M, Damalas CA. Occupational exposure to pesticides and resultant health problems among cotton farmers of Punjab, Pakistan. Int J Environ Health Res. 2015;25(5):508-21.

67. Salameh PR, Abi Saleh B. Symptoms and acute pesticide intoxication among agricultural workers in Lebanon. J Med Liban. 2004;52(2):64-70.

68. Souza A, Medeiros, Reis A, Souza AC, Wink M, Siqueira IR, et al. Avaliação do impacto da exposição a agrotóxicos sobre a saúde de população rural: Vale do Taquari (RS, Brasil). Cien Saude Colet [Internet]. 2011 [citado em 2018 Jun 13];16(8):3519-28. Disponível em: http://www. scielo.br/scielo.php?script $=$ sci_arttext\&pid $=$ S1413$81232011000900020 \& \operatorname{lng}=\mathrm{pt} \& \overline{\mathrm{t}} \operatorname{lng}=\mathrm{pt}$

69. Jacobson LSV, Hacon SS, Alvarenga L, Goldstein RA, Gums C, Buss DF, et al. Comunidade pomerana e uso de agrotóxicos: uma realidade pouco conhecida. Cien Saude Colet [Internet]. 2009 [citado em 13 jun 2018];14(6):2239-49. Disponível: http://www. scielo.br/scielo.php?script $=$ sci_arttext\&pid $=$ S141381232009000600033\&lng $=$ pt\&tlng $=$ pt

70. Siqueira D, Moura R, Laurentino G, Araújo A, Cruz S. Qualidade de vida de trabalhadores rurais e agrotóxicos: um estudo com o Whoqol-Bref. Rev Bras Ciênc Saúde [Internet]. 2013 [acesso 10 Abr 2018];17(2):139-48. Disponível em: http:// periodicos.ufpb.br/ojs2/index.php/rbcs/article/ view/13145/9707

71. Alavanja MCR, Hofmann JN, Lynch CF, Hines CJ, Barry KH, Barker J, et al. Non-Hodgkin lymphoma risk and insecticide, fungicide and fumigant use in the agricultural health study. PLoS One [Internet]. 2014 [cited 2018 May 29];9(10): e109332. Available from: http://journals.plos. org/plosone/article/file?id=10.1371/journal. pone.0109332\&type $=$ printable

72. Lerro CC, Koutros S, Andreotti, G, Frieses MC, C AM, Blair A, et al. Organophosphate insecticide use and cancer incidence among spouses of pesticide applicators in the Agricultural Health Study. Occup Environ Med [Internet]. 2015 [cited 2018 June 13];72(10):736-44. Available from: https://oem.bmj. com/content/oemed/72/10/736.full.pdf

73. Engel LS, Hill DA, Hoppin JA, Lubin JH, Lynch CF, Pierce J, et al. Pesticide use and breast cancer risk among farmers' wives in the agricultural health study. Am J Epidemiol [Internet]. 2005 [cited 2018 May 29];161(2):121-35. Available from: https:// academic.oup.com/aje/article/161/2/121/256660

74. Lerro CC, Koutros S, Andreotti G, Hines CJ, Blair A, Lubin J, et al. Use of acetochlor and cancer incidence in the Agricultural Health Study. Int J cancer [Internet]. 2015 [cited 2018 Aug 20];137(5):1167-75. Available from: https:// onlinelibrary.wiley.com/doi/epdf/10.1002/ijc.29416

75. International Agency for Research on Cancer. IARC Monographs Volume 112: evaluation of five organophosphate insecticides and herbicides [Internet]. Lyon; 2015 [cited 2018 May 10]. Available from: https://www.iarc.fr/en/mediacentre/iarcnews/pdf/MonographVolume112.pdf

76. Alavanja MCR. Use of agricultural pesticides and prostate cancer risk in the agricultural health study cohort. Am J Epidemiol [Internet]. 2003 [cited 2018 May 13];157(9):800-14. Available from: https:// academic.oup.com/aje/article-lookup/doi/10.1093/ aje/kwg040

77. Peres F, Rozemberg B. É veneno ou é remédio? Os desafios da comunicação rural sobre agrotóxicos. In: Peres F, Moreira JC, organizadores. É veneno ou é remédio? agrotóxicos, saúde e ambiente. Rio de Janeiro: Fiocruz; 2003. p. 329-48.

78. de Carvalho WO. Construção de questionário para uso em inquéritos de base populacional: notas metodológicas 1. Ciênc Cuid Saúde [Internet]. 2006 [citado em 27 abr 2018];5:92-8. Disponível: http://www.periodicos.uem.br/ojs/index.php/ CiencCuidSaude/article/view/5172/3345

79. Agência Nacional de Vigilância Sanitária (BR). Programa de Análise de resíduos de agrotóxicos em alimentos (PARA). Relatório complementar relativo à segunda etapa das análises de amostras coletadas em 2012. Brasília: Agência Nacional de Vigilância Sanitária; 2014.

80. Baird C. Química ambiental. 2 ed. Porto Alegre: Bookman; 2002.

81. Bolognesi C. Genotoxicity of pesticides: a review of human biomonitoring studies. Mutat Res. 2003;543: 251-27. 
82. Oliveira-Silva JJ, Alves SR, Della-Rosa HV. Avaliação da exposição humana a agrotóxicos. In: Peres F, Moreira JC, organizadores. E veneno ou é remédio? agrotóxicos, saúde e ambiente. Rio de Janeiro: Fiocruz; 2003. p. 121-36.

83. Klassen CD. Cassarett and Doull's Toxicology: the basic science of poison. 8 ed. United States: McGraw-Hill Education; 2013

84. Friedrich K. Desafios para a avaliação toxicológica de agrotóxicos no Brasil: desregulação endócrina e imunotoxicidade. ViSa em Debate [Internet]. 2013 [citado em 27 abr 2018];1(2):2-15. Disponível em: https://visaemdebate.incqs.fiocruz.br/index.php/ visaemdebate/article/view/30

85. Agência Nacional de Vigilância Sanitária (BR). Listas de ingredientes ativos com uso autorizado e banidos no Brasil. 2017.

86. Pesticide Action Network International. PAN International Consolidated List of Banned Pesticides [Internet]. 2017 [cited 2018 May 10]. Available from: http://pan-international.org/pan-internationalconsolidated-list-of-banned-pesticides/

87. Carneiro FF, Rigotto RM, Augusto LG da S, Friedrich K, Búrigo AC. Dossiê Abrasco: um alerta sobre os impactos doas agrotóxicos na saúde. Rio de Janeiro/ São Paulo: EPSJV/Expressão Popular; 2015

88. Roberts JR, Reigart JR. Recognition and management of pesticide poisonings. 6 ed. Washington: US Environmental Protection Agency's, Office of Pesticide Programs; 2013

89. Faria NMX, Fassa AG, Facchini LA. Intoxicação por agrotóxicos no Brasil: os sistemas oficiais de informação e desafios para realização de estudos epidemiológicos. Ciênc Saúde Colet [Internet]. 2007 [citado em 4 jun 2019];12(1):25-38. Disponível: http://www.scielo.br/pdf/csc/v12n1/04.pdf
90. Larini L. Toxicologia dos Praguicidas. São Paulo: Manole; 1999.

91. Extension Toxicology Network. Cholinesterase inhibition [Internet]. United States: Cornell University, Oregon State University, the University of Idaho, and the University of California at Davis and the Institute for Environmental Toxicology, Michigan State University; 1993 [cited 2018 June 10]. Available from: http://extoxnet.orst.edu/ tibs/cholines.htm

92. International Agency for Research on Cancer. IARC Monographs on the identification of carcinogenic hazards to humans - preamble [Internet]. Lyon; 2019 [cited 2019 Jun 4]. Available from: https:// monographs.iarc.fr/wp-content/uploads/2019/01/ Preamble-2019.pdf

93. Szwarcwald CL, Damacena GN, Souza Júnior PRB, Almeida WS, Lima LTM, Malta DC, et al. Determinantes da autoavaliação de saúde no Brasil e a influência dos comportamentos saudáveis: resultados da Pesquisa Nacional de Saúde. Rev Bras Epidemiol [Internet]. 2015 [citado em 10 jun 2018];18(2):33-44. Disponível: http://www.scielo.br/scielo.php?pid=S1415790X2015000600033\&script $=$ sci_abstract\&tlng $=p t$

94. Moreira JPL, Oliveira BLCA, Muzi CD, Cunha CLF, Brito AS, Luiz RR. A saúde dos trabalhadores da atividade rural no Brasil. Cad Saude Publica [Internet]. 2015 [citado em 13 jun 2018];31(8):1698-708. Disponível: https://www.scielo.br/scielo.php?script=sci arttext\&pid $=$ S0102-311X2015000801698\&lng $=p$ t\&tlng $=\mathrm{pt}$

95. Santos M, Viana M. Atlas do agronegócio: fatos e números sobre as corporações que controlam o que comemos. Rio de Janeiro: Fundação Heinrich Böll; 2018. 